\title{
Performance and Characteristics of Wearable Sensor Systems Discriminating and Classifying Older Adults According to Fall Risk: A Systematic Review
}

\author{
Annica Kristoffersson ${ }^{1}\left(\mathbb{D}\right.$, Jiaying $\mathrm{Du}^{2}$ and Maria Ehn ${ }^{1, * \mathbb{C}}$ \\ 1 School of Innovation, Design and Engineering, Mälardalen University, 72220 Västerås, Sweden; \\ annica.kristoffersson@mdh.se \\ 2 Motion Control i Västerås AB, 72130 Västerås, Sweden; jiaying.du@motioncontrol.se \\ * Correspondence: maria.ehn@mdh.se; Tel.: +46-21-107093
}

Citation: Kristoffersson, A.; Du, J.; Ehn, M. Performance and Characteristics of Wearable Sensor Systems Discriminating and Classifying Older Adults According to Fall Risk: A Systematic Review. Sensors 2021, 21, 5863. https:// doi.org/10.3390/s21175863

Academic Editor: Kamiar Aminian

Received: 19 May 2021

Accepted: 27 August 2021

Published: 31 August 2021

Publisher's Note: MDPI stays neutral with regard to jurisdictional claims in published maps and institutional affiliations.

Copyright: (C) 2021 by the authors Licensee MDPI, Basel, Switzerland. This article is an open access article distributed under the terms and conditions of the Creative Commons Attribution (CC BY) license (https:/ / creativecommons.org/licenses/by/ $4.0 /)$.

\begin{abstract}
Sensor-based fall risk assessment (SFRA) utilizes wearable sensors for monitoring individuals' motions in fall risk assessment tasks. Previous SFRA reviews recommend methodological improvements to better support the use of SFRA in clinical practice. This systematic review aimed to investigate the existing evidence of SFRA (discriminative capability, classification performance) and methodological factors (study design, samples, sensor features, and model validation) contributing to the risk of bias. The review was conducted according to recommended guidelines and 33 of 389 screened records were eligible for inclusion. Evidence of SFRA was identified: several sensor features and three classification models differed significantly between groups with different fall risk (mostly fallers/non-fallers). Moreover, classification performance corresponding the AUCs of at least 0.74 and/or accuracies of at least $84 \%$ were obtained from sensor features in six studies and from classification models in seven studies. Specificity was at least as high as sensitivity among studies reporting both values. Insufficient use of prospective design, small sample size, low insample inclusion of participants with elevated fall risk, high amounts and low degree of consensus in used features, and limited use of recommended model validation methods were identified in the included studies. Hence, future SFRA research should further reduce risk of bias by continuously improving methodology.
\end{abstract}

Keywords: fall risk; classification; assessment; older adults; inertial sensors; wearable sensors

\section{Introduction}

Falls are the second leading cause of accidental or unintentional injury resulting in death worldwide [1]. Approximately 35\% of all people aged 65 years or older fall every year [2] and the incidence of falls increases with age [3]. Important risk factors include impaired balance and gait performance, polypharmacy, and a history of previous falls [4]. Interventions combining fall preventive physical activities with strategies to increase safety in home environments have proven to be the most effective in reducing the incidence and risk of falls [5]. Technologies can improve fall prevention interventions' efficiency and effectiveness. Hence, fall prevention technologies are mainly used to assess and decrease fall risk, to increase adherence to fall prevention training interventions or to detect occurring falls and alarms in case of an accident [6].

Sensor-based fall risk assessment (SFRA) utilizes wearable sensors for monitoring individuals' motions during assessment tasks. The sensor signals are processed, and specific features are extracted and incorporated into algorithms which aim at predicting fall occurrence or classifying individuals into risk categories [7]. Several reviews of stateof-the-art of SFRA research were published during 2012-2019.

In 2012, Shany et al. discussed the practicalities and challenges associated with the use of wearable sensors for the quantification of older people's fall risk [7]. They identified 
several study design elements that need to be fulfilled in order to support future real-life use of SFRA. These include: (1) prospective design, (2) larger validations of higher quality enabling meta-analyses, (3) rigorous testing including reliability of test-retest and ratereffects, (4) validation of SFRA-tools on different samples and by research groups other than those suggesting/developing the tool, and (5) an increased focus on SFRA supporting clinical staff in supervised assessments [7].

The following year, Howcroft et al. (2013) made a systematic review of SFRA in geriatric populations using inertial sensors. The review was based on 40 articles published 2003-March 2013 and confirmed the need of prospective design in SFRA research [8]. Moreover, Howcroft et al. emphasized the need to use separate datasets in training and validation of classification models, and more appropriate intelligent computing methods, such as neural networks and Bayesian classifiers, instead of regression [8]. The use of separate datasets had been neglected in $50 \%$ of the studies involving classification models included in the review [8]. Howcroft et al. also identified a need for: (1) systematically assessing which combinations of body locations of sensors and sensor-based variables result in high reliability, (2) investigating long-term user compliance to SFRA methods, (3) using SFRA in specialized populations, systematic matching of predictive variables and specific fall risk factors, and (4) comparing accuracies of SFRA methods with accuracies of clinical assessments, both obtained by prospective studies [8].

In 2015, Shany et al. published a review of articles including features extracted from sensor signals in statistical models intended to estimate fall risk or predict falls in older people [9]. This review, which was based on 31 articles published 1997-2015, identified problems with publication bias, inadequate sample sizes, inadequate number of fall events in samples, misuse and lack of model validation, deficiencies in model selection and feature extraction procedures, and insufficient use of prospective fall occurrence as serious issues [9]. Shany et al. (2015) pointed out that some of the included studies reported classification accuracies exceeding the estimated theoretical maximal accuracy (0.81) in predicting the occurrence of a fall during a one-year period [10]. They concluded that the prediction performance was overestimated in the literature, mainly due to small samples, large feature pools, model overfitting, lack of validation, and misuse of modelling techniques [9]. Therefore, Shany et al. suggested that sample bias should be prevented by recruiting cohorts ensuring that an adequate number of falls occur and by considering the recommendations of 1:10 features/event [11] during feature selection [9]. They also suggested improvements in feature selection by tightening the significance thresholds, removing redundant features, and selecting the correct statistical methods [9]. Finally, the need for appropriate model validation methods, preferably by external validation of the final model, was stressed [9].

Roeing et al. [12] conducted a review on the use of mobile health applications for assessment of balance, i.e., one of the fall risk factors. The article included 13 articles published 2011-2016. Several of the articles included young samples, while others lacked information on the studied group of participants. Five articles assessed the validity of mobile health applications by comparing the data collected with data collected using 3D motion capture measurement, an accelerometer or a force platform.

Three systematic reviews were published in 2018 [13-15]. Sun and Sosnoff [13] reviewed the use of novel sensing technology in fall risk assessment in 22 articles published 2011-May 2017. Their recommendations for future research included the use of: (1) prospective fall occurrence of at least 6 months to label subjects, (2) a reduced number of variables, selection of variables based on previous research, and (3) appropriate model validation [13].

Montesinos et al. [14] presented a systematic review and meta-analysis of the use of wearable inertial sensors for fall risk assessment and prediction in older adults. The review included 13 articles published up until 2016. Montesinos et al. [14] identified strong/very strong associations between fall risk assessment outcomes and nine triads (combinations of a sensor feature category, a task, and a sensor placement). The recommended and not-recommended triads were found to be task-dependent when analyzing the tasks quiet 
standing, sit-to-stand/stand-to-sit, Timed Up and Go (TUG) test and walking. For both quiet standing and sit-to-stand/stand-to-sit, the recommended feature category and sensor location were linear acceleration and lower back. For TUG, the recommended sensor category and sensor location were temporal and shins. For walking, there existed both recommended and not-recommended triads. The recommended combinations of sensor feature category and sensor location for walking task were: (1) angular velocity-shins, (2) frequency-upper back, and (3) frequency-lower back. The not-recommended combinations of sensor category and sensor location during walking were: (1) angular velocitylower back, (2) frequency-shins, and (3) linear acceleration-shins. Hence, the sensor location recommended by [14] varies depending on the feature category, particularly for walking.

Rucco et al. [15] reviewed the type and location of wearable sensors for monitoring falls during static and dynamic tasks in healthy elderly. The review was based on 42 articles published 2002-2017. Rucco et al. concluded that the majority of studies used a maximum of two sensors with accelerometers and gyroscopes being the most common, and that the majority of studies presented preliminary results [15]. The trunk was identified as the most studied body segment. The most frequently used tasks varied depending on whether the task was static or dynamic. For measuring static stability, a quiet standing test with eyes opened/closed was most common. For dynamic evaluations, the most common tasks were walking and stand-sit tests [15]. Finally, Rucco et al. [15] stated that information on performance, i.e., accuracy, sensitivity, and specificity, was too diverse and did not allow for evaluating the impact of different system characteristics. Therefore, they identified the need for golden standards in terms of sensors (types, position) and tasks.

In 2019, Bet et al. made a systematic review on fall detection and fall risk assessment in older persons using wearable sensors [16]. The review, which was based on 29 different articles published 2002-2019, presented performance metrics and reported on number of sensors, sensor types, sensor location and assessment tasks. It should be noted that 20 of the articles included only accelerometer features. The use of other sensors was sparse, one article used only gyroscope features, five used a combination of accelerometer and gyroscope features, two used a combination of accelerometer and barometer features, and one used a combination of accelerometer, gyroscope, and magnetometer features. Bet et al. also analyzed sensor locations and found that the most common location was the waist (8 articles), followed by the lumbar region (7), ankle (4), pelvis (4), and head (3) [16].

It is worth noticing here that different terminologies have potentially been used to denote the same sensor location in previous review articles. For example, Montesinos et al. [14], who identified recommended and not-recommended triads, used the notation shins in their triads, while Bet et al. [16] identified four articles with sensors located on the ankle. Further, the most frequently used locations in [16] were the waist and lower back (lumbar spine) whereas [14] stated that the most common placement was the lower back (approximately L3). Rucco et al. [15] used the notation trunk for sensors located at L3, L5, sternum, waist, pelvis, neck, and chest. Hence, comparing the results obtained in this review with results from the previous reviews is not straightforward.

The aim of this systematic review was to analyze the characteristics and performance of wearable sensor systems used to assess older people's fall risk by classifying individuals according to fall risk or by discriminating between groups of older people with different fall risk. The following research questions were in focus:

RQ1 What is the evidence of SFRA in terms of (a) discriminative capability, and (b) classification performance?

RQ2 Which of the previously identified risk factors for study bias can be identified among the included studies? The risk factors analyzed included: (a) low use of prospective study design, (b) use of small study samples with low amounts of fall events, (c) low consensus in features used in SFRA models; and (d) misuse of model validation methods. 


\section{Materials and Methods}

\subsection{Literature Search}

The systematic literature review was conducted according to the PRISMA guidelines [17]. The review elements (aim including PICO elements, eligibility criteria and outcomes) are defined in Table 1.

Table 1. Review elements.

\begin{tabular}{|c|c|c|}
\hline Objective/Aim & Inclusion Criteria & Exclusion Criteria \\
\hline $\begin{array}{l}\text { To make a systematic review of the } \\
\text { performance of wearable sensor systems } \\
\text { in discriminating/classifying older adults } \\
\text { according to their fall risk. } \\
\text { The following PICO elements [18] were } \\
\text { used: } \\
\text { Population of interest: Persons being } 60 \\
\text { years and older without severe cognitive } \\
\text { impairment. } \\
\text { Investigated test result: Person classified } \\
\text { as faller according to SFRA } \\
\text { Comparator test result: Person classified } \\
\text { as non-faller according to SFRA } \\
\text { Outcome: Person classified as faller (or } \\
\text { equivalent, e.g., high risk) according to } \\
\text { Retrospective falls history (RE), } \\
\text { Prospective fall occurrence (PRO) or } \\
\text { Clinical assessment methods (CLIN) } \\
\text { Study design: Prospective and } \\
\text { Cross-Sectional studies }\end{array}$ & $\begin{array}{l}\text { 1. Original, peer-reviewed journal } \\
\text { articles/conference papers published and } \\
\text { indexed during Jan } 2010-\text { April } 2020 \text { in } \\
\text { English language. } \\
\text { 2. Participants labelled as } \\
\text { (single/multiple-) fallers/non-fallers or } \\
\text { high/low risk based on: } \\
\text { a. RE data } \\
\text { b. PRO data } \\
\text { c. CLIN data } \\
\text { d. A combination of a-c } \\
\text { 3. Sample: N } \geq 10 \text {, age } \geq 60 \text { years } \\
\text { 4. Wearable or mobile inertial sensors } \\
\text { used to characterize movements by } \\
\text { extracting features from sensor signals. } \\
\text { 5. Evidence of SFRAs in terms of } \\
\text { (a) discriminative capacity (statistically } \\
\text { significant discriminatory features) } \\
\text { and/or } \\
\text { (b) classification performance (accuracy, } \\
\text { sensitivity, specificity). } \\
\text { Inclusion criteria 2-4 were based on a } \\
\text { previous systematic review of SFRA [14]. }\end{array}$ & $\begin{array}{l}\text { Papers must not include participants } \\
\text { with severe cognitive impairment, e.g., } \\
\text { dementia. } \\
\text { Papers must not only include } \\
\text { measurements of total physical activity } \\
\text { by activity monitors. } \\
\text { Outcomes }\end{array}$ \\
\hline
\end{tabular}

The systematic literature search was done in four databases: Web of Science Core Collection (i.e., SCI-EXPANDED, SSCI, A\&HCI, CPCI-S, CPCI-SSH and ESCI), IEEE Xplore, Pubmed, and Medline. Search phrases and search dates for each database are presented in Table 2. Web of Science and IEEE Xplore were searched twice with modifications made in search phrases.

\subsection{Study Selection}

The systematic literature search in the four databases identified 614 records. After removal of 225 duplicates, 389 publications were screened for eligibility according to the inclusion and exclusion criteria in Table 1. The titles and abstracts of potentially relevant articles were screened independently by two researchers (ME and AK). Eligibility assessments of full text records were performed independently by the same two researchers. In both steps, disagreement was resolved through discussions until consensus was reached. A total of 304 articles were excluded in the screening. Full text copies were downloaded for the remaining 33 articles included in this review (Figure 1).

\subsection{Data Extraction}

Data from the full text articles was extracted to a study specific template with defined variables (Table A1 in Appendix A). Data extraction was performed independently by three researchers (ME, AK, and JD). All reported data/results were discussed by at least two researchers until consensus was reached. 
Table 2. An overview of databases, search phrases used during article retrieval, and information on search dates. The numbers indicate the number of identified articles in each search.

\begin{tabular}{|c|c|c|c|}
\hline Database & Search Phrase & Search Date & $\begin{array}{l}\text { Number of } \\
\text { Articles }\end{array}$ \\
\hline $\begin{array}{l}\text { Web of Science Core } \\
\text { Collection }\end{array}$ & $\begin{array}{l}\text { TOPIC: (fall AND risk AND assessment) AND } \\
\text { TOPIC:(inertial sensors) AND TOPIC:(geriatric OR older } \\
\text { OR senior) AND TOPIC: (clinical) }\end{array}$ & 20 September 2019 & 31 \\
\hline IEEE Xplore & $\begin{array}{l}\text { TOPIC: (fall AND risk AND assessment) AND } \\
\text { TOPIC:(inertial sensors) AND TOPIC:(geriatric OR older } \\
\text { OR senior) AND TOPIC: (clinical) }\end{array}$ & 30 October 2019 & 21 \\
\hline $\begin{array}{l}\text { Web of Science Core } \\
\text { Collection }\end{array}$ & $\begin{array}{l}\text { TOPIC: ((fall AND risk AND assessment) AND (inertial } \\
\text { sensors OR wearable OR technology OR device OR } \\
\text { accelerometer OR gyroscope OR magnetometer) AND } \\
\text { (geriatric OR older OR senior OR old) AND (clinical)) }\end{array}$ & 6 March 2020 & 129 \\
\hline IEEE Xplore & $\begin{array}{l}\text { TOPIC: fall AND risk AND assessment AND clinical AND } \\
\text { (“inertial sensors" OR wearable OR technology OR device } \\
\text { OR accelerometer OR gyroscope OR magnetometer) AND } \\
\text { (geriatric OR older OR old OR senior) } \\
\text { Filters Applied: Conferences Journals }\end{array}$ & 12 March 2020 & 32 \\
\hline Pubmed & $\begin{array}{l}(((\text { fall[All Fields] AND ("risk"[MeSH Terms] OR “risk"[All } \\
\text { Fields])) AND ("Assessment"[Journal] OR “assessment"[All } \\
\text { Fields])) AND clinical[All Fields]) AND (geriatric[All } \\
\text { Fields] OR older[All Fields] OR old[All Fields] OR } \\
\text { senior[All Fields])) AND ("inertial sensors"[All Fields] OR } \\
\text { wearable[All Fields] OR ("technology"[MeSH Terms] OR } \\
\text { "technology"[All Fields]) OR ("equipment and } \\
\text { supplies"[MeSH Terms] OR ("equipment"[All Fields] AND } \\
\text { "supplies"[All Fields]) OR “equipment and supplies"[All } \\
\text { Fields] OR “device"[All Fields]) OR accelerometer[All } \\
\text { Fields] OR gyroscope[All Fields] OR magnetometer[All } \\
\text { Fields]) }\end{array}$ & 27 March 2020 & 120 \\
\hline Medline & $\begin{array}{l}\text { fall AND risk AND assessment AND clinical AND ("inertial } \\
\text { sensors" OR wearable OR technology OR device OR } \\
\text { accelerometer OR gyroscope OR magnetometer) AND } \\
\text { (geriatric OR older OR old OR senior) } \\
\text { Expanders } \\
\text { Limiters: Apply equivalent subjects } \\
\text { Journals: Scholarly (Peer Reviewed) Journals } \\
\text { Source Types: Academic Journals } \\
\text { Language: English }\end{array}$ & 3 April 2020 & 281 \\
\hline
\end{tabular}

\subsection{Research Questions and Data Analysis}

The study's two main research questions were:

RQ1 What is the evidence of SFRA in terms of (a) discriminative capacity, and (b) classification performance?

RQ2 Which of the previously identified risk factors for study bias can be identified among the included studies? The risk factors analyzed included: (a) low use of prospective study design, (b) use of small study samples with low amounts of fall events, (c) low consensus in features used in SFRA models, and (d) misuse of model validation methods.

In order to guide the analysis of the collected data, a larger number of more detailed research questions were formulated. These questions guided how the data, collected in the study specific data collection template (Appendix A), were summarized and presented in eight tables. Table 3 and Section 3.1 present data on study characteristics; Tables 4-6 and Sections 3.2 and 3.3 present data on fall risk assessment system 
characteristics. Table 4 presents articles performing discrimination by feature selection. Tables 5 and 6 present articles performing classification methods/models with and without machine learning algorithms. Section 3.4 presents the results of an analysis on whether Montesinos et al.'s triads [14] can be identified in the included articles and whether the triad theory applies also on articles using classification models. Tables 7-10 and Section 3.5 present data on the evaluation methodology and fall risk discrimination/ classification performance.

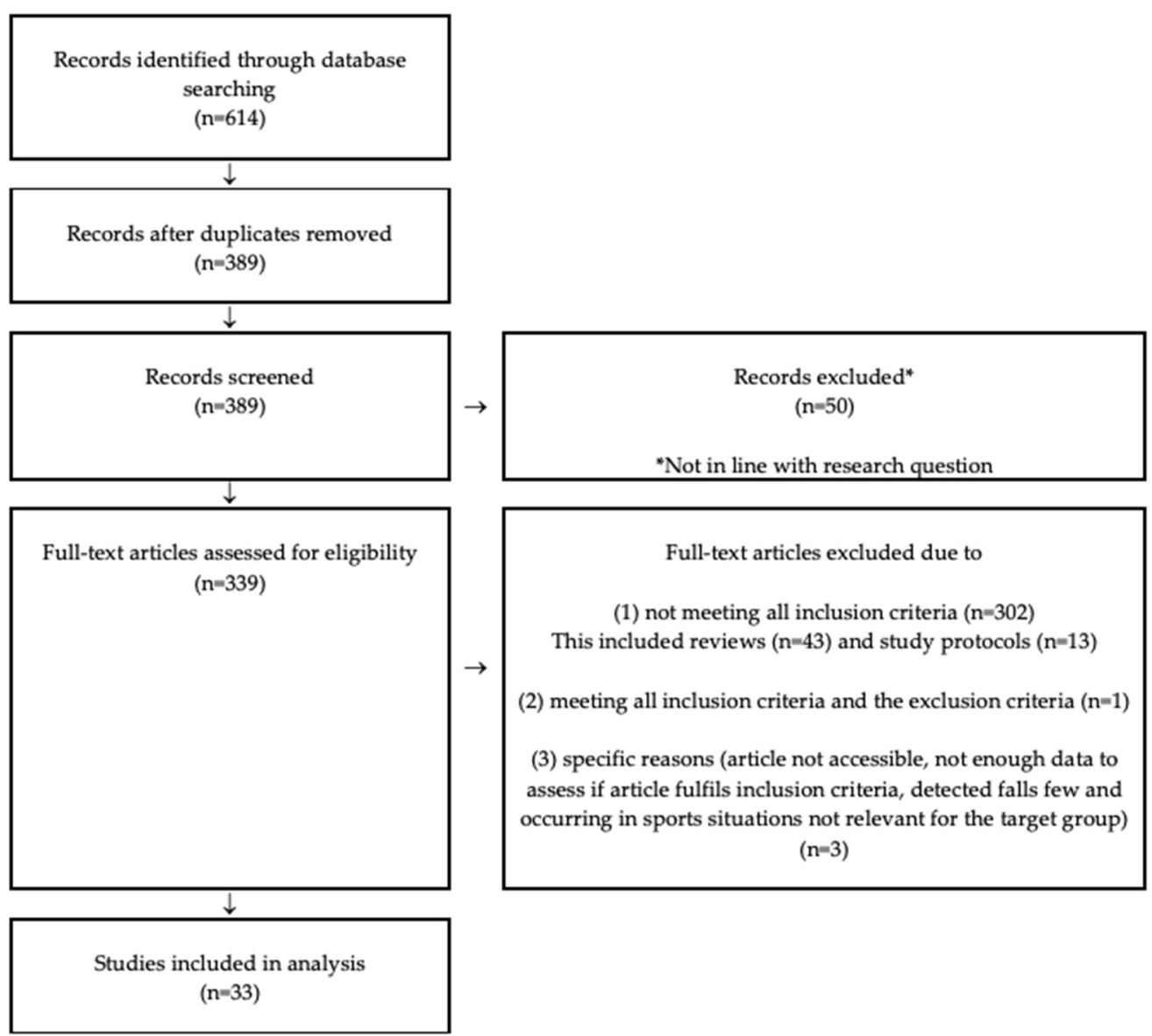

Figure 1. Flow diagram of articles identified and evaluated based on eligibility criteria.

Qualitative data were analyzed according to content and quantitative data were analyzed using descriptive statistics if possible.

\section{Results}

The presented results include study characteristics (Section 3.1), wearable sensors used for fall risk assessment (Section 3.2), signal processing (Section 3.3), the identification of triads and assessment of their applicability on classification methods/models (Section 3.4), and statistical analysis on the sensor-based methods' capabilities to assess fall risk (Section 3.5).

The studies were published between January 2010 and December 2019. The number of articles per year was highest in $2017(n=8)$ followed by 2011, 2016, 2018, and 2019 $(n=5)$, and $2014(n=3)$. Only one article from 2013 and 2015 respectively is included. None of the included articles were published in 2010, 2012, or 2020.

\subsection{Study Characteristics}

The characteristics of the 33 included studies are presented in Table 3. 
Table 3. Characteristics of included studies. ADL = activity in daily life, FoF = Fear of Falling, FTSS = 5 times Sit-to-stand test, SEMI-SUP $=$ Semi-supervised, SUP $=$ Supervised, $6 \mathrm{MWT}=$ Six-Minutes Walking Test, UEF $=$ Upper extremities function, UNSUP = Unsupervised, Val = Validation, VR = Virtual reality.

\begin{tabular}{|c|c|c|c|c|c|c|c|}
\hline $\begin{array}{l}\text { First Author, } \\
\text { Year }\end{array}$ & Ref No. & $\begin{array}{l}\text { Study } \\
\text { Population }\end{array}$ & $\begin{array}{l}\text { Faller/Non-Faller } \\
\text { Labelling Method }\end{array}$ & $\begin{array}{l}\text { Classification } \\
\text { Outcome }\end{array}$ & $\begin{array}{l}\text { Participants } \\
\text { (\% Fallers) }\end{array}$ & $\begin{array}{l}\text { Assessment } \\
\text { Task }\end{array}$ & $\begin{array}{l}\text { Degree of } \\
\text { Supervision }\end{array}$ \\
\hline $\begin{array}{l}\text { Bautmans, } \\
2011\end{array}$ & [19] & Other & $\begin{array}{l}\text { Retrospective falls } \\
\text { (6 months) and } \\
\text { Clinical assessment } \\
\text { (Tinetti, TUG) }\end{array}$ & non-faller/faller & $81(49 \%)$ & $\begin{array}{l}\text { Walking } \\
(2 \times 18 \mathrm{~m})\end{array}$ & SUP \\
\hline Caby, 2011 & {$[20]$} & $\begin{array}{l}\text { Hospitalized } \\
\text { patients }\end{array}$ & $\begin{array}{l}\text { Retrospective falls } \\
\text { (12 months) and } \\
\text { Clinical assessment } \\
\text { (Tinetti, Mini } \\
\text { Motor Test) }\end{array}$ & $\begin{array}{l}\text { non-faller not at } \\
\text { risk/faller at risk } \\
\text { of falling }\end{array}$ & $20(75 \%)$ & Walking $(25 \mathrm{~m})$ & SUP \\
\hline Doheny, 2011 & {$[21]$} & $\begin{array}{l}\text { Community- } \\
\text { dwelling }\end{array}$ & $\begin{array}{l}\text { Retrospective falls } \\
\text { (60 months) and } \\
\text { Clinical assessment } \\
\text { (FoF and } \\
\text { Cardiovascular } \\
\text { risk factors) }\end{array}$ & $\begin{array}{l}\text { non-faller/faller } \\
(\geq 2 \text { falls } / 1 \text { fall } \\
\text { seeking } \\
\text { medical care })\end{array}$ & $39(49 \%)$ & FTSS & SUP \\
\hline Greene, 2011 & {$[22]$} & $\begin{array}{l}\text { Community- } \\
\text { dwelling }\end{array}$ & $\begin{array}{l}\text { Retrospective falls } \\
\text { (60 months) }\end{array}$ & non-faller/faller & $114(47 \%)$ & $\begin{array}{l}\text { Walking ( } 30 \mathrm{~m} \\
\text { continuous) }\end{array}$ & SUP \\
\hline $\begin{array}{l}\text { Marschollek, } \\
2011\end{array}$ & [23] & $\begin{array}{l}\text { Patients, } \\
\text { geriatric }\end{array}$ & $\begin{array}{l}\text { Prospective falls } \\
\text { (12 months) }\end{array}$ & non-faller/faller & $46(41 \%)$ & $\begin{array}{l}\text { TUG test } \\
\text { Walking }(20 \mathrm{~m})\end{array}$ & SUP \\
\hline Doi, 2013 & {$[24]$} & $\begin{array}{l}\text { Community- } \\
\text { dwelling }\end{array}$ & $\begin{array}{l}\text { Prospective falls } \\
\text { (12 months) }\end{array}$ & non-faller/faller & $73(22 \%)$ & $\begin{array}{l}\text { Walking } \\
(15 \mathrm{~m})\end{array}$ & SUP \\
\hline Cui, 2014 & [25] & $\begin{array}{l}\text { Community- } \\
\text { dwelling }\end{array}$ & $\begin{array}{l}\text { Retrospective falls } \\
\text { (12 months) }\end{array}$ & $\begin{array}{l}\text { non-faller/faller } \\
(\geq 2 \text { falls })\end{array}$ & $81(49 \%)$ & $\begin{array}{l}\text { Walking } \\
\text { ( } 3 \text { conditions) }\end{array}$ & SUP \\
\hline Ejupi, 2014 & [26] & $\begin{array}{l}\text { Community- } \\
\text { dwelling }\end{array}$ & $\begin{array}{l}\text { Retrospective falls } \\
\text { (12 months) }\end{array}$ & non-faller/faller & $104(35 \%)$ & $\begin{array}{l}\text { Choice } \\
\text { Stepping } \\
\text { Reaction Test }\end{array}$ & SUP \\
\hline Greene, 2014 & [27] & $\begin{array}{l}\text { Community- } \\
\text { dwelling }\end{array}$ & $\begin{array}{l}\text { Retrospective falls } \\
\text { (60 months) } \\
\text { and } \\
\text { Prospective falls } \\
\text { ( } 24 \text { months) }\end{array}$ & non-faller/faller & $\begin{array}{l}\text { RE: } 909 \text { (NA) } \\
\text { PRO: } 259 \text { (NA) } \\
\text { Val: } 55(0 \%)\end{array}$ & TUG test & SUP \\
\hline Brodie, 2015 & {$[28]$} & $\begin{array}{l}\text { Community- } \\
\text { dwelling }\end{array}$ & $\begin{array}{l}\text { Prospective falls } \\
\text { (12 months) }\end{array}$ & $\begin{array}{l}\text { non- } \\
\text { faller/faller/multi- } \\
\text { faller }\end{array}$ & $\begin{array}{l}52(42 \% \text { single, } \\
17 \% \text { multi) }\end{array}$ & Stair ascent & $\begin{array}{l}\text { SEMI-SUP } \\
\text { at research } \\
\text { facility }\end{array}$ \\
\hline Howcroft, 2016 & [29] & Other & $\begin{array}{l}\text { Retrospective falls } \\
\text { (6 months) }\end{array}$ & non-faller/faller & $100(24 \%)$ & $\begin{array}{l}\text { Walking } \\
\text { (7.62 m, single- } \\
\text { and dual-task } \\
\text { condition) }\end{array}$ & SUP \\
\hline Ihlen, 2016 & {$[30]$} & $\begin{array}{l}\text { Community- } \\
\text { dwelling }\end{array}$ & $\begin{array}{l}\text { Retrospective falls } \\
\text { (12 months) }\end{array}$ & $\begin{array}{l}\text { non-faller/faller } \\
\text { ( } \geq 2 \text { falls) }\end{array}$ & $71(45 \%)$ & $\begin{array}{l}4 \text { FTSS at home } \\
\text { for } \\
1 \text { day }\end{array}$ & $\begin{array}{l}\text { SUP } \\
\text { at home }\end{array}$ \\
\hline Ihlen, 2016 & {$[31]$} & $\begin{array}{l}\text { Community- } \\
\text { dwelling }\end{array}$ & $\begin{array}{l}\text { Retrospective falls } \\
\text { (12 months) }\end{array}$ & $\begin{array}{l}\text { non-faller/faller } \\
(\geq 2 \text { falls })\end{array}$ & $71(45 \%)$ & $\begin{array}{l}\text { Walking } \\
\text { (daily life) }\end{array}$ & $\begin{array}{l}\text { UNSUP } \\
3 \text { days at } \\
\text { home }\end{array}$ \\
\hline Iluz, 2016 & {$[32]$} & Other & $\begin{array}{l}\text { Retrospective falls } \\
\text { (12 months) }\end{array}$ & $\begin{array}{l}\text { non-faller/faller } \\
\text { ( } \geq 2 \text { falls) }\end{array}$ & $71(46 \%)$ & $\begin{array}{l}\text { ADL } \\
\text { (identified } \\
\text { sit-to-walk and } \\
\text { walk-to-sit } \\
\text { transitions) }\end{array}$ & $\begin{array}{l}\text { UNSUP } \\
3 \text { days } \\
\text { at home }\end{array}$ \\
\hline Mancini, 2016 & [33] & Other & $\begin{array}{l}\text { Retrospective falls } \\
\text { (12 months) } \\
\text { and } \\
\text { Prospective falls } \\
\text { (6 months) }\end{array}$ & $\begin{array}{l}\text { non- } \\
\text { faller/faller/multiple- } \\
\text { faller }(R E) \\
\text { non-faller }(P R O)\end{array}$ & $\begin{array}{l}35 \text { (RE: } 34 \% \\
\text { single, 20\% } \\
\text { multi; PRO: } \\
20 \% \text { ) }\end{array}$ & ADL & $\begin{array}{l}\text { UNSUP } \\
1 \text { week } \\
\text { at home }\end{array}$ \\
\hline
\end{tabular}


Table 3. Cont.

\begin{tabular}{|c|c|c|c|c|c|c|c|}
\hline $\begin{array}{l}\text { First Author, } \\
\text { Year }\end{array}$ & Ref No. & $\begin{array}{l}\text { Study } \\
\text { Population }\end{array}$ & $\begin{array}{l}\text { Faller/Non-Faller } \\
\text { Labelling Method }\end{array}$ & $\begin{array}{l}\text { Classification } \\
\text { Outcome }\end{array}$ & $\begin{array}{l}\text { Participants } \\
\text { (\% Fallers) }\end{array}$ & $\begin{array}{l}\text { Assessment } \\
\text { Task }\end{array}$ & $\begin{array}{l}\text { Degree of } \\
\text { Supervision }\end{array}$ \\
\hline $\begin{array}{l}\text { Alqahtani, } \\
2017\end{array}$ & {$[34]$} & $\begin{array}{l}\text { In residential } \\
\text { care }\end{array}$ & $\begin{array}{l}\text { Retrospective falls } \\
\text { (12 months) }\end{array}$ & non-faller/faller & $29(66 \%)$ & $\begin{array}{l}\text { Standing } \\
\text { balance test }\end{array}$ & SUP \\
\hline Brodie, 2017 & {$[35]$} & $\begin{array}{l}\text { Community- } \\
\text { dwelling }\end{array}$ & $\begin{array}{l}\text { Retrospective falls } \\
\text { (12 months) }\end{array}$ & non-faller/faller & $96(34 \%)$ & ADL & $\begin{array}{l}\text { UNSUP, } \\
1 \text { week at } \\
\text { home }\end{array}$ \\
\hline Greene, 2017 & [36] & $\begin{array}{l}\text { Community- } \\
\text { dwelling }\end{array}$ & $\begin{array}{l}\text { Retrospective falls } \\
\text { (12 months) }\end{array}$ & non-faller/faller & $22(50 \%)$ & TUG test & SUP \\
\hline Joseph, 2017 & [37] & $\begin{array}{l}\text { Patients, } \\
\text { bedbound in } \\
\text { hospital }\end{array}$ & $\begin{array}{l}\text { Clinical assessment } \\
\text { (UEF index) }\end{array}$ & frail/non-frail & $101(52 \%)$ & $\begin{array}{l}\text { UEF } \\
\text { assessment }\end{array}$ & SUP \\
\hline Saldana, 2017 & [38] & $\begin{array}{l}\text { In continuing- } \\
\text { care retirement } \\
\text { community }\end{array}$ & $\begin{array}{l}\text { Clinical assessment } \\
\text { (Questions including } \\
\text { retrospective falls } \\
\text { and FoF) }\end{array}$ & low-risk/at-risk & $13(38 \%)$ & $\begin{array}{l}\text { Standing } \\
\text { balance with } \\
\text { VR room } \\
\text { rotation }\end{array}$ & SUP \\
\hline Sample, 2017 & [39] & Other & $\begin{array}{l}\text { Retrospective falls } \\
\text { (12 months) }\end{array}$ & non-faller/faller & $148(40 \%)$ & TUG test & SUP \\
\hline Smith, 2017 & [40] & $\begin{array}{l}\text { Community- } \\
\text { dwelling }\end{array}$ & $\begin{array}{l}\text { Retrospective falls } \\
\text { (12 months) }\end{array}$ & non-faller/faller & $37(43 \%)$ & $\begin{array}{l}\text { TUG test } \\
\text { (single-, motor- } \\
\text { and cognitive } \\
\text { dual task) }\end{array}$ & SUP \\
\hline Wang, 2017 & [41] & $\begin{array}{l}\text { Community- } \\
\text { dwelling }\end{array}$ & $\begin{array}{l}\text { Prospective falls } \\
\text { (12 months) }\end{array}$ & $\begin{array}{l}\text { multiple- } \\
\text { faller/non- } \\
\text { multiple-faller }\end{array}$ & $81(14 \%)$ & $\begin{array}{l}\text { Walking (flat } \\
\text { surface } \\
\text { and stairs) }\end{array}$ & $\begin{array}{l}\text { SEMI-SUP } \\
\text { at research } \\
\text { facility }\end{array}$ \\
\hline Bizovska, 2018 & [42] & Other & $\begin{array}{l}\text { Prospective falls } \\
\text { (12 months) }\end{array}$ & $\begin{array}{l}\text { non-faller/faller/ } \\
\text { multiple-faller }\end{array}$ & $\begin{array}{l}131(27 \%, \\
\text { multi } 11 \%)\end{array}$ & Walking (25 m) & SUP \\
\hline Ehsani, 2018 & [43] & Other & $\begin{array}{l}\text { Clinical assessment } \\
\text { (Questions including } \\
\text { retrospective falls, } \\
12 \text { months) }\end{array}$ & $\begin{array}{l}\text { high fall-risk/low } \\
\text { fall-risk }\end{array}$ & $20(50 \%)$ & $\begin{array}{l}\text { Upright } \\
\text { standing } \\
\text { balance (eyes } \\
\text { open/closed, } \\
\text { with/without } \\
\text { vibration) }\end{array}$ & SUP \\
\hline Genovese, 2018 & [44] & Patients & $\begin{array}{l}\text { Determined by } \\
\text { clinical partners }\end{array}$ & $\begin{array}{l}\text { high fall-risk/ } \\
\text { age matched low } \\
\text { fall-risk }\end{array}$ & $50(50 \%)$ & $6 \mathrm{MWT}$ & SUP \\
\hline $\begin{array}{l}\text { Ghahramani, } \\
2018\end{array}$ & {$[45]$} & $\begin{array}{l}\text { Community- } \\
\text { dwelling }\end{array}$ & $\begin{array}{l}\text { Retrospective falls } \\
\text { (time period } \\
\text { not presented) }\end{array}$ & $\begin{array}{l}\text { non- } \\
\text { faller/multiple- } \\
\text { faller }\end{array}$ & 45 (49\% multi) & Turning test & SUP \\
\hline Qiu, 2018 & [46] & $\begin{array}{l}\text { Community- } \\
\text { dwelling } \\
\text { females }\end{array}$ & $\begin{array}{l}\text { Retrospective falls } \\
\text { (60 months) }\end{array}$ & non-faller/faller & $196(42 \%)$ & $\begin{array}{l}\text { Battery of } \\
\text { clinical tests } \\
\text { including } \\
\text { assessment of } \\
\text { standing } \\
\text { balance, } \\
\text { stability, } \\
\text { sit-stand- } \\
\text { transitions, } \\
\text { walking, motor } \\
\text { function, } \\
\text { reaction } \\
\text { and FoF }\end{array}$ & SUP \\
\hline Del Din, 2019 & [47] & Other & $\begin{array}{l}\text { Retrospective falls } \\
(6 \text { months }(\geq 2 \text { falls to } \\
\text { identify fallers) and } \\
18 \text { months } \\
\text { ( } 0 \text { falls to identify } \\
\text { non-faller }) \text { ) }\end{array}$ & non-faller/faller & $172(71 \%)$ & Free living gait & $\begin{array}{l}\text { UNSUP, } \\
1 \text { week } \\
\text { at home }\end{array}$ \\
\hline
\end{tabular}


Table 3. Cont.

\begin{tabular}{|c|c|c|c|c|c|c|c|}
\hline $\begin{array}{l}\text { First Author, } \\
\text { Year }\end{array}$ & Ref No. & $\begin{array}{l}\text { Study } \\
\text { Population }\end{array}$ & $\begin{array}{l}\text { Faller/Non-Faller } \\
\text { Labelling Method }\end{array}$ & $\begin{array}{l}\text { Classification } \\
\text { Outcome }\end{array}$ & $\begin{array}{l}\text { Participants } \\
\text { (\% Fallers) }\end{array}$ & $\begin{array}{l}\text { Assessment } \\
\text { Task }\end{array}$ & $\begin{array}{l}\text { Degree of } \\
\text { Supervision }\end{array}$ \\
\hline $\begin{array}{l}\text { Ghahramani, } \\
2019\end{array}$ & [48] & $\begin{array}{l}\text { Community- } \\
\text { dwelling }\end{array}$ & $\begin{array}{l}\text { Retrospective falls } \\
\text { (12 months) }\end{array}$ & $\begin{array}{l}\text { non-faller/faller/ } \\
\text { multiple-faller }\end{array}$ & $\begin{array}{l}86 \text { ( } 21 \% \text { single, } \\
44 \% \text { multi) }\end{array}$ & $\begin{array}{l}\text { Standing } \\
\text { balance tests }\end{array}$ & SUP \\
\hline Greene, 2019 & [49] & $\begin{array}{l}\text { Stratified } \\
\text { sample }\end{array}$ & $\begin{array}{l}\text { Retrospective falls } \\
\text { (12 months) }\end{array}$ & non-faller/faller & $\begin{array}{l}6295(14 \% \\
\text { single, } 12 \% \\
\text { multi) }\end{array}$ & TUG test & SUP \\
\hline Misu, 2019 & [50] & $\begin{array}{l}\text { Community- } \\
\text { dwelling }\end{array}$ & $\begin{array}{l}\text { Retrospective falls } \\
\text { (12 months) }\end{array}$ & $\begin{array}{l}\text { RE-12 } \\
\text { non-faller/faller }\end{array}$ & $378(17 \%)$ & Walking (15 m) & SUP \\
\hline Yang, 2019 & [51] & $\begin{array}{l}\text { Community- } \\
\text { dwelling }\end{array}$ & $\begin{array}{l}\text { Retrospective falls } \\
\text { (3 months) }\end{array}$ & $\begin{array}{l}\text { non-faller/faller/ } \\
\text { multiple-faller }\end{array}$ & $\begin{array}{l}40 \text { ( } 20 \% \text { single, } \\
40 \% \text { multi) }\end{array}$ & ADL & $\begin{array}{l}\text { UNSUP, } \\
1 \text { week } \\
\text { at home }\end{array}$ \\
\hline
\end{tabular}

\subsubsection{Authors Involved and Places Where the Research Was Conducted}

The 33 included articles were authored by 145 authors affiliated in 16 countries on four continents (Asia, Europe, North America, and Oceania). Five authors were affiliated with organizations in two different countries. Most authors (116/145) authored one article. However, 21 authored two articles and eight authors were in the author list of at least four articles (number of articles in parenthesis): Brodie (4), Caulfield (4), Delbaere (4), Greene (6), Hausdorff (5), Lord (4), Redmond (4), and Weiss (4).

Most articles (25/33) were written by authors affiliated in the same country. The distribution per continent was as follows: Asia: Israel $(n=1)$, Japan $(n=2)$, South Korea $(n=1)$; Europe: Belgium $(n=1)$, Germany $(n=1)$, Ireland $(n=4)$, Italy $(n=1)$; North America: Canada $(n=2)$, United States $(n=6)$ : and Oceania: Australia $(n=6)$. Eight articles had authors affiliated in different countries: Australia-Ireland $(n=1)$, Ireland-USA $(n=1)$, Israel-Taiwan-USA $(n=1)$, Israel-Norway $(n=1)$, Germany-Israel-Norway $(n=1)$, Czech Republic-France-Italy $(n=1)$, Belgium-Netherlands $(n=1)$, Belgium-Israel-ItalyNetherlands-UK-USA $(n=1)$. It is worth noting that the Australian articles were authored by two groups, one group authoring [45,48], and another group authoring [25,28,35,41]. Greene was on the author list of all articles from Ireland and on the author list of the Australia-Ireland and Ireland-USA articles. The USA articles were almost exclusively written by different research groups although two authors were on the author list for $2 / 6$ articles from USA. The articles including authors from Israel were mostly authored in collaboration with authors from other countries.

\subsubsection{Study Populations}

The study participants were classified as community-dwelling (18 articles), patients (four articles), residential care/continuing-care retirement community (two articles), and other (eight articles) if none of the aforementioned labels matched the reported population (e.g., "people from cohort," or "convenience sample"). In addition, one study [49] had a large, stratified sample including subgroups of community-dwelling, residential care, and patients (neurological and rehabilitation). The populations of all studies per publication year are presented in Figure 2. Community-dwelling was the most studied population, and none of the other populations were studied in publications from 2013-2015. No other clear trends could be identified among the included studies in study population.

\subsubsection{Faller/Non-Faller (or Equivalent) Labelling Method}

The studies generated outcomes to compare SFRAs by labelling the participants according to their fall risk. Although the most common outcome was non-faller/faller, other labels, namely frail/non-frail [37], low risk/at-risk [38,43,44] were also used. Moreover, [42,48,51] used three labels (non-faller/faller/multiple-faller). 


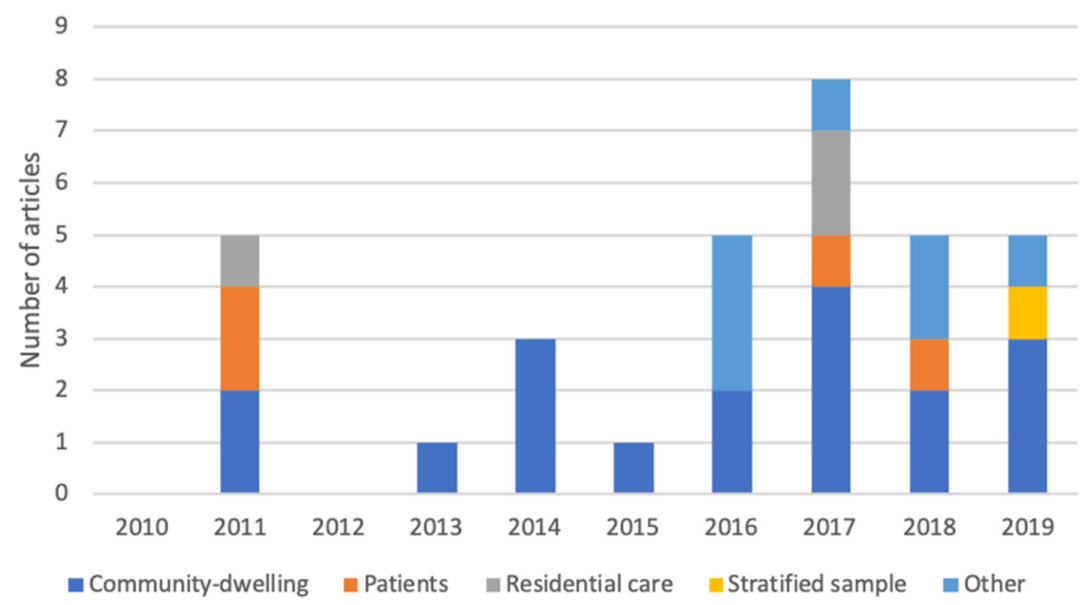

Figure 2. Number of studies per study population and publication year.

The most common method to label a participant as faller or a non-faller (or equivalent) was RE data alone $(n=18)$ or in combination with CLIN data $(n=4)$. Three of the included studies solely used CLIN data (formulas or functional tests) to label participants. However, two of these studies used clinical formulas which included RE data. Five studies used PRO data alone and two studies combined RE and PRO data (one of them compared performance of retrospective and prospective classification models [27]). Finally, one study [44] stated that clinical partners determined whether a participant was labelled as high fall risk or age matched low fall risk. This technique was categorized as "other" in the current review (Figure 3 and Table 4). Figure 3 presents the number of studies per publication year that applied the respective faller/non-faller (or equivalent) labelling method. As can be seen here, the use of PRO data (alone or in combination with RE data) had not increased during 2011-2019. In total, seven studies used PRO data, either alone or in combination with RE data, to label participants. PRO data was mainly followed up for 12 months (5/7 studies), although 6- and 24-months periods were also used. In total, 25 studies used RE data to label participants (either alone, in combination with PRO and CLIN data, or as part of CLIN data). RE data was mostly retrieved from the past 12 (16/25 studies), 60 (5/25 studies), 6 ( $2 / 25$ studies), 3 ( $1 / 25$ studies) or 18 months ( $1 / 25$ studies). Moreover, one study did not specify the length of the period to collect RE data.

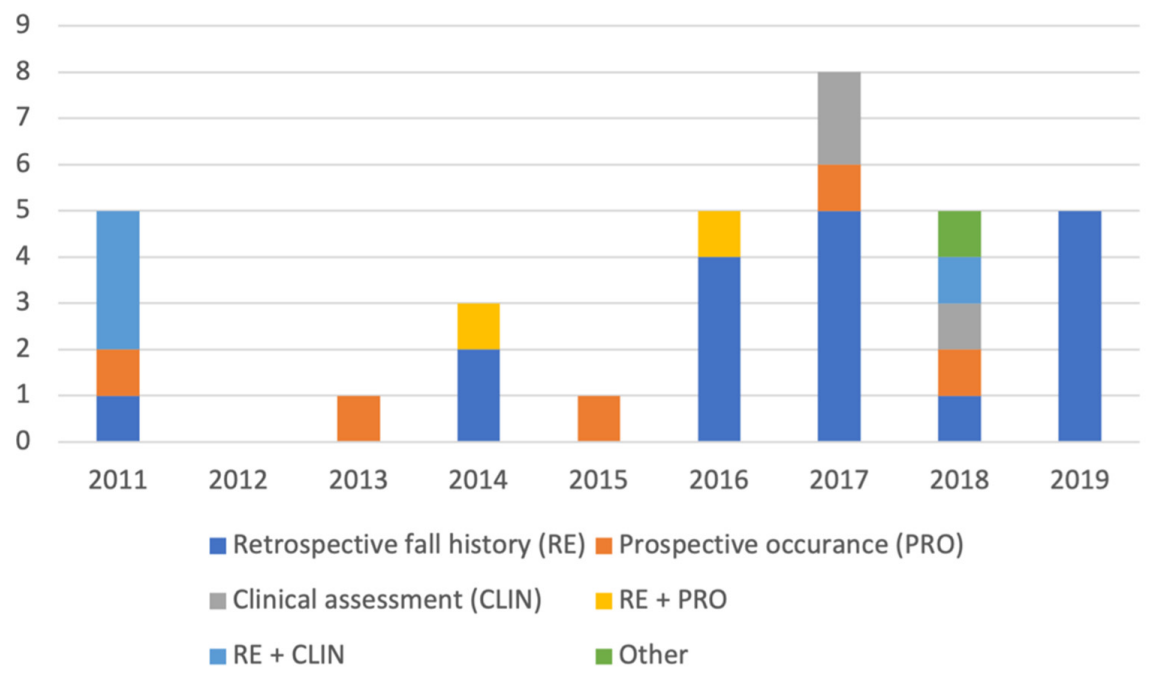

Figure 3. Number of studies per faller/non-faller (or equivalent) labelling method and publication year. 


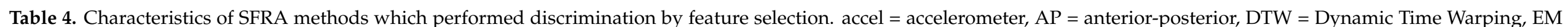

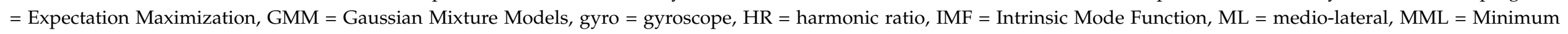

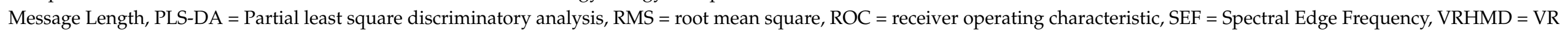
head-mounted display, VT = vertical.

\begin{tabular}{|c|c|c|c|c|c|c|}
\hline Ref No. & Assessment Task & $\begin{array}{l}\text { No. and Type of } \\
\text { Wearable Sensor(s) }\end{array}$ & Sensor Position(s) & $\begin{array}{l}\text { No. of Sensor } \\
\text { Features }\end{array}$ & Feature Selection Methods & $\begin{array}{l}\text { Wearable Sensor Features Able to } \\
\text { Discriminate Significantly } \\
\text { between Fallers/Non-Fallers }\end{array}$ \\
\hline [19] & $2 \times 18 \mathrm{~m}$ walking & $13 \mathrm{D}$ accel & $\begin{array}{l}\text { Pelvis (sacrum between } \\
\text { the spinae ilaca posterior } \\
\text { superior) }\end{array}$ & 6 & $\begin{array}{l}\text { ANOVA and } t \text {-test, } \\
\text { Wilcoxon-signed-rank, } \\
\text { Kruskall-Wallis tests, stepwise } \\
\text { logistic regression with forward } \\
\text { likelihood ratio and ROC curve }\end{array}$ & Gait speed \\
\hline [21] & FTSS & $\begin{array}{l}2 \text { inertial sensors (3D } \\
\text { accel data used) }\end{array}$ & $\begin{array}{l}\text { Anterior of right thigh, } \\
\text { sternum }\end{array}$ & 19 & ANOVA and one-way ANOVA & $\begin{array}{l}\text { Mean sit-stand-time, total jerk, total } \\
\text { SEF, Mean sit-stand-sit SEF, } \\
\text { Mean-stand-sit SEF, Mean sit-stand } \\
\text { SEF }\end{array}$ \\
\hline [24] & $15 \mathrm{~m}$ walking & $23 \mathrm{D}$ accel & $\begin{array}{l}\text { Upper trunk (C7 spinous } \\
\text { process) and lower trunk } \\
\text { (L3 spinous process) }\end{array}$ & 6 & $\begin{array}{l}\text { Independent } t \text {-tests or } \chi 2 \text { tests, } \\
\text { stepwise logistic regression with } \\
\text { forward stepwise selection and } \\
\text { ROC curve }\end{array}$ & HR in VT direction in Upper trunk \\
\hline [25] & $\begin{array}{l}\text { Walking under } 3 \text { different } \\
\text { conditions }\end{array}$ & $\begin{array}{l}1 \text { inertial sensor (3D } \\
\text { accel data used) }\end{array}$ & Lower back (belt) & $1^{1}$ & $\begin{array}{l}\text { Wilcoxon Signed Rank and Mann } \\
\text { Whitney test }\end{array}$ & SSI \\
\hline [26] & $\begin{array}{l}\text { Choice stepping Reaction } \\
\text { Test (in exergame) }\end{array}$ & $13 \mathrm{D}$ accel & $\begin{array}{l}\text { Around neck (sternum } \\
\text { height) inside clothes }\end{array}$ & 6 & Two-sided Student's $t$-test & Reaction time, Total stability time \\
\hline [30] & $\begin{array}{l}4 \text { FTSS at home for } \\
1 \text { day }\end{array}$ & $\begin{array}{l}1 \text { inertial sensor (3D } \\
\text { accel data used) }\end{array}$ & $\begin{array}{l}\text { Lower back (belt } \\
\text { around waist) }\end{array}$ & $1^{2}$ & $\begin{array}{l}\text { Univariate logistic regression and } \\
\text { stepwise multivariate logistic } \\
\text { regression with stepwise backward } \\
\text { feature selection }\end{array}$ & $\begin{array}{l}\text { LDS calculated by the Ihlen } \\
\text { algorithm (Equation (2)) [52] with } \\
\text { optimal identified parameter setting }\end{array}$ \\
\hline [31] & Daily life walking & $\begin{array}{l}1 \text { inertial sensor (3D } \\
\text { accel data used) }\end{array}$ & Lower back (belt) & 60 & $\begin{array}{l}\text { PLS-DA with a backward } \\
\text { feature selection }\end{array}$ & $\begin{array}{l}\text { RCME and RMPE for trunk } \\
\text { acceleration and trunk velocity }\end{array}$ \\
\hline
\end{tabular}


Table 4. Cont.

\begin{tabular}{|c|c|c|c|c|c|c|}
\hline Ref No. & Assessment Task & $\begin{array}{l}\text { No. and Type of } \\
\text { Wearable Sensor(s) }\end{array}$ & Sensor Position(s) & $\begin{array}{l}\text { No. of Sensor } \\
\text { Features }\end{array}$ & Feature Selection Methods & $\begin{array}{l}\text { Wearable Sensor Features Able to } \\
\text { Discriminate Significantly } \\
\text { between Fallers/Non-Fallers }\end{array}$ \\
\hline [33] & ADL & $\begin{array}{l}3 \text { inertial sensors ( } 3 \mathrm{D} \\
\text { gyro data used) }\end{array}$ & $\begin{array}{l}\text { Posterior trunk at about } \\
\text { L5 (belt) and on the top } \\
\text { of each foot (on shoes) }\end{array}$ & 6 & One-way ANOVA & $\begin{array}{l}\text { RE-12: turn duration, mean peak } \\
\text { speed of turning, mean number of } \\
\text { steps/turns, Coefficient of Variation } \\
\text { of turn angle; } \\
\text { PRO-6: Coefficient of Variation of } \\
\text { steps per turn }\end{array}$ \\
\hline [34] & Standing balance test & $\begin{array}{l}12 \mathrm{D} \text { accel and } 1 \mathrm{D} \\
\text { load cell }\end{array}$ & Pelvis (Iliac crest) & 16 & $\begin{array}{l}\text { Friedman test, Wilcoxon signed } \\
\text { ranks test, Spearman rank } \\
\text { correlation and Mann-Whitney } \\
\text { U test }\end{array}$ & $\begin{array}{l}\text { RMS sway acceleration in ML } \\
\text { direction during } \\
\text { semi-tandem stance }\end{array}$ \\
\hline [35] & ADL & $13 \mathrm{D}$ accel + barometer & Pending around neck & 7 & $\begin{array}{l}\text { ANOVA, ANCOVA, Pearson's } \\
\text { correlation and Partial } \\
\text { Pearson's correction }\end{array}$ & $\begin{array}{l}\text { Gait endurance and within walk } \\
\text { variability in daily life }\end{array}$ \\
\hline [37] & UEF assessment & $23 \mathrm{D}$ gyro & $\begin{array}{l}\text { Upper arm (near the } \\
\text { biceps and to wrist) }\end{array}$ & 8 & $\begin{array}{l}\text { ANOVA, Logistic regression (for } \\
\text { nominal health outcomes) and } \\
\text { ANOVA regression (for continuous } \\
\text { health outcomes) }\end{array}$ & $\begin{array}{l}\text { UEF index including speed, power } \\
\text { and speed reduction }\end{array}$ \\
\hline [38] & $\begin{array}{l}\text { Standing balance with VR } \\
\text { room rotation }\end{array}$ & $\begin{array}{l}1 \text { VRHMD (6D inertial } \\
\text { sensor + camera) and a } \\
\text { force plate }\end{array}$ & Head & $\begin{array}{l}10 \text { under each } \\
\text { condition }\end{array}$ & $\begin{array}{l}\text { One-sample } t \text {-test, signed rank test, } \\
\text { paired } t \text {-test and } \\
\text { Pearson's correlation }\end{array}$ & $\begin{array}{l}\text { VRHMD AP velocity while eyes } \\
\text { open in VR module "balance" }\end{array}$ \\
\hline [39] & TUG test & $\begin{array}{l}4 \text { inertial sensor (3D } \\
\text { accel and } 3 \mathrm{D} \text { gyro) and a } \\
\text { force plate }\end{array}$ & $\begin{array}{l}\text { Chest, lower back, } \\
\text { each foot }\end{array}$ & $\begin{array}{l}8 \text { (plus } 9 \\
\text { post-urography } \\
\text { parameters) }\end{array}$ & $\begin{array}{l}\text { Stepwise logistic regression and } \\
\text { Pearson correlation }\end{array}$ & $\begin{array}{l}\text { Combination of Sit-to-Stand } \\
\text { Duration, Stand-to-Sit Duration, } \\
\text { Turn Peak Velocity, AP Sway } \\
\text { Range, Height }\end{array}$ \\
\hline [40] & $\begin{array}{l}\text { TUG test under single- } \\
\text { motor- and cognitive } \\
\text { dual task }\end{array}$ & $\begin{array}{l}2 \text { inertial sensors (3D } \\
\text { accel and 3D gyro) }\end{array}$ & Anterior of shank (shin) & 10 & MANCOVA and ANCOVA & Cadence, stride velocity, stride time \\
\hline
\end{tabular}


Table 4. Cont.

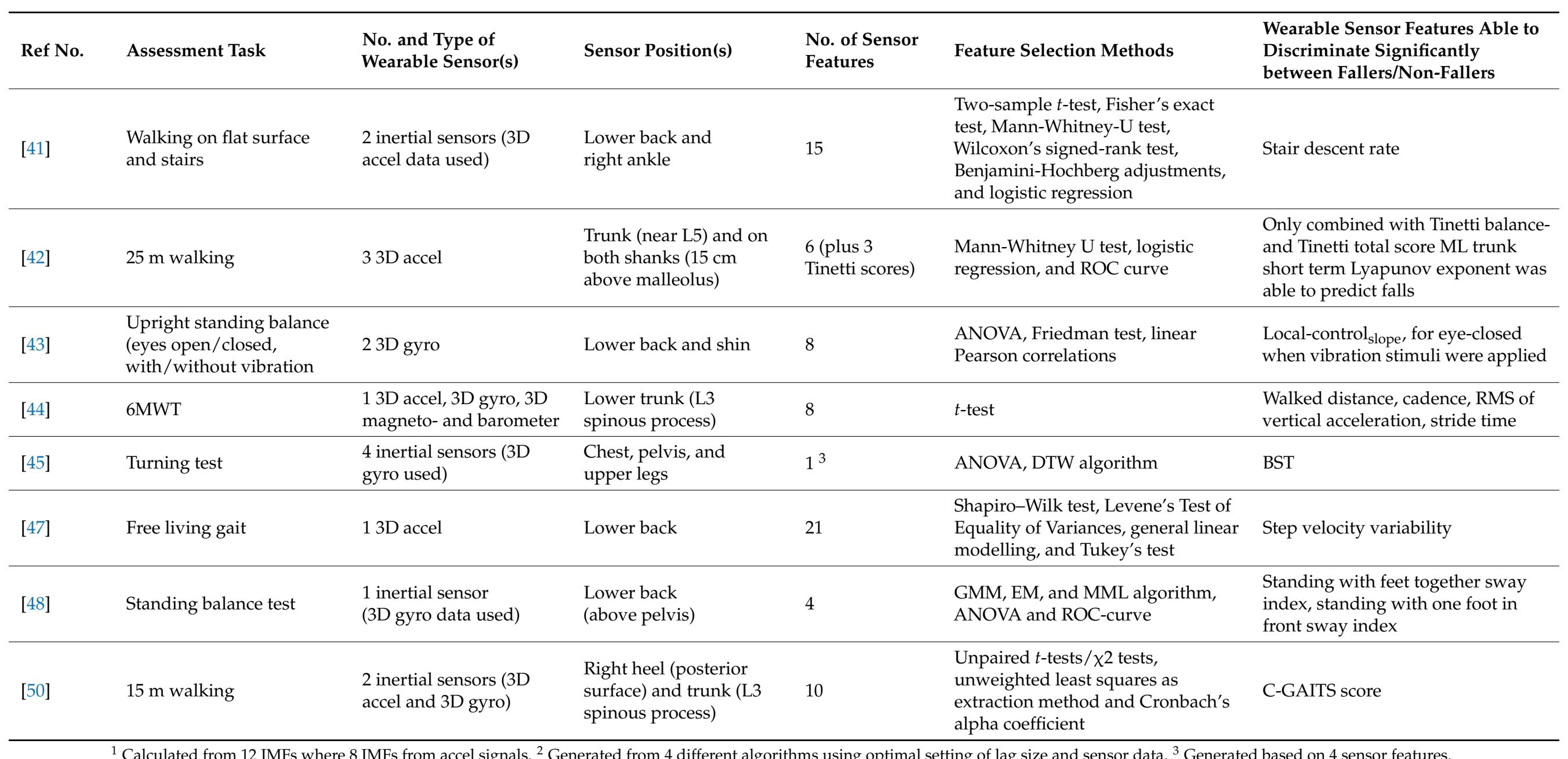

${ }^{1}$ Calculated from 12 IMFs where 8 IMFs from accel signals. ${ }^{2}$ Generated from 4 different algorithms using optimal setting of lag size and sensor data. ${ }^{3}$ Generated based on 4 sensor features. 


\subsubsection{Size and Proportion of Participants Labelled as Fallers of Study Samples}

The studies' sample sizes ranged from 13 to 6295 participants (mean 289, median 73, standard deviation (SD) 1041). One study used three different datasets [27], which were counted as three separate samples in our analysis. One study published in 2019 [49] had an exceptionally large sample of 6295 participants. The studies were categorized into eight categories according to sample size. The distribution of studies for each categorized sample size is presented in Figure 4. Approximately one third (12/35) of the studies had a sample of at least 100 participants.

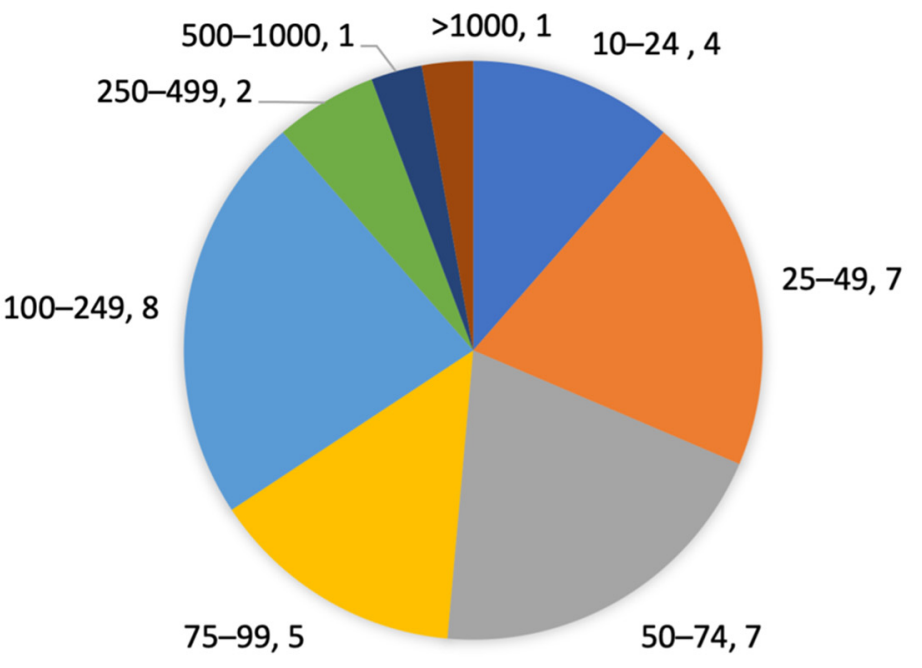

Figure 4. Distribution of study samples according to size.

The proportion of participants labelled as having elevated fall risk (faller, frail or at risk) according to RE data (recorded during periods of 3-60 months) and/or PRO data (during periods of 6-24 months) and/or CLIN data ranged from $14 \%$ to $71 \%$ (mean $44 \%$, median $46 \%$, SD 14.7\%), see Table 3. The threshold used to define a person with elevated fall risk (faller, frail or at risk) varied between the studies. For example, while most studies required at least one previous fall to label a participant as a faller in some studies, a few studies (pointed out in Table 3) required at least two falls. Moreover, most studies performed binary classification of participants (faller/non-faller) while a few studies classified participants into three groups (faller/once-faller/multiple faller). One of the study samples in [27] did not specify the percentage of fallers in sample, the sample was therefore omitted in the analysis. Moreover, one study used both RE and PRO data to label participants and obtained different proportion of fallers depending on method. Both values were included in the analysis.

\subsubsection{Sensor-Based Fall Risk Assessment Tasks and Degree of Supervision}

Most of the studies (25/33) performed supervised SFRAs where assessment tasks tested walking $(n=9)$, sit-to-stand transitions in combination with walking (mostly in TUG) $(n=6)$, standing balance function $(n=4)$, sit-to-stand transitions $(n=2)$, turning balance $(n=1)$, choice stepping reaction time $(n=1)$, upper extremity function $(n=1)$, and TUG in combination with other clinical tests $(n=1)$. Two of the supervised tests were performed in a home setting. In two of the 33 studies, the SFRAs tasks (walking on flat surface and stairs and stair ascent) were performed in semi-supervised conditions at research facilities. Six of the 33 studies analyzed sensor data from unsupervised assessment tasks in a home environment, either ADL or free-living daily gait.

The number of different fall risk assessment tasks identified in this review was higher than the four tasks (quiet standing, sit-to-stand/stand-to-sit, TUG and walking) included in the triads identified in by [14]. 
Studies basing SFRA on classification methods/models with machine learning used fewer assessment than studies basing SFRA on feature selection and on classification models without machine learning. In addition, the use of unsupervised and semi-supervised assessments was higher among studies using classification methods/models with machine learning (50\% supervised, $33 \%$ unsupervised and $17 \%$ semi-supervised) than among studies performing discrimination by feature selection ( $77 \%$ supervised, $18 \%$ unsupervised and $5 \%$ semi-supervised) and studies using classification models without machine learning (100\% supervised).

\subsection{Wearable Sensor Used for Fall Risk Assessment}

This section provides an overview of trends in the number of wearable sensors and sensor types used, as well as the distribution of wearable sensors at different body locations. The identified differences between studies performing discrimination by feature selection and studies using classification methods/models with and without machine learning algorithms are presented.

\subsubsection{Number of Wearable Sensors}

The average number of sensors per study varied between 1 and 5 among the articles. Most studies (26/33) used 1-2 sensors. As shown in Figure 5, the variation in average number of sensors used per article and year was higher for studies using classification methods/models (i.e., studies in Tables 5 and 6 where the number varied between 1 and 10) than for studies not using classification methods/models (i.e., the studies in Table 4 where the number varied between 1 and 4). However, the difference in average number of sensors per publication year was not statistically significant between the two groups of studies.

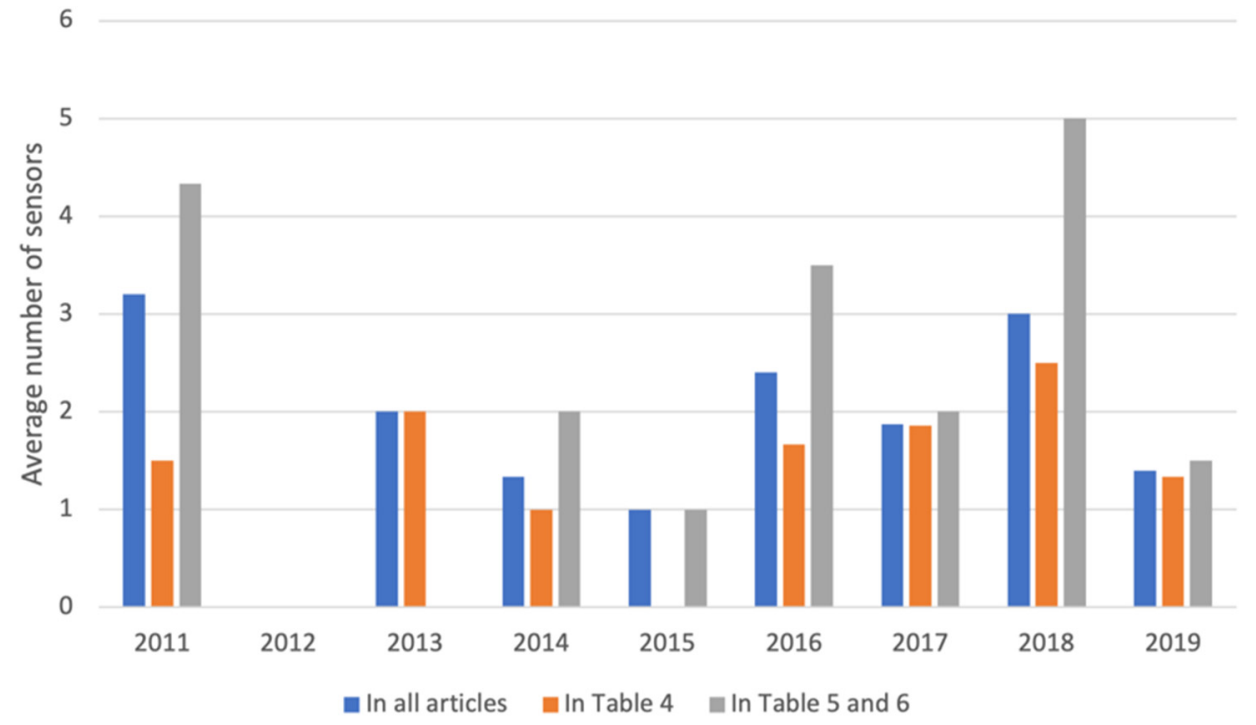

Figure 5. Average number of sensors per publication year for: (1) all articles, (2) the articles in Table 4, and (3) the articles in Tables 5 and 6. 


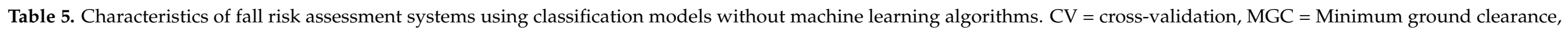
SagAngVel = Angular velocity in the sagittal plane.

\begin{tabular}{|c|c|c|c|c|c|c|}
\hline Ref No. & Assessment Task & $\begin{array}{l}\text { No. and Type of } \\
\text { Wearable Sensor(S) }\end{array}$ & Sensor Position(s) & $\begin{array}{l}\text { No. of Sensor } \\
\text { Features }\end{array}$ & Feature Selection Methods & $\begin{array}{l}\text { Models Able to Discriminate } \\
\text { Significantly between } \\
\text { Fallers/Non-Fallers }\end{array}$ \\
\hline [22] & $30 \mathrm{~m}$ continuous walk & $\begin{array}{l}2 \text { inertial sensors (3D } \\
\text { accel and 3D gyro) }\end{array}$ & $\begin{array}{l}\text { Mid-point of } \\
\text { anterior shank }\end{array}$ & 10 & $\begin{array}{l}\text { Mann-Whitney Wilcoxon rank } \\
\text { sum and Pearson's correlation }\end{array}$ & $\begin{array}{l}\text { MGC estimation by regression models } \\
\text { (MGC model and MGC variance model) } \\
\text { using the features mean SagAngVel at } \\
\text { mid-swing points, mean absolute } \\
\text { valued SagAngVel and min SagAngVel }\end{array}$ \\
\hline [23] & TUG test and $20 \mathrm{~m}$ walk & $13 \mathrm{D}$ accel & $\begin{array}{l}\text { Lower back (belt } \\
\text { around waist) }\end{array}$ & 14 & $\begin{array}{l}\text { Wrapper feature selection } \\
\text { algorithm (wrapper subset } \\
\text { evaluator employing the simple } \\
\text { logistic algorithm) }\end{array}$ & $\begin{array}{l}\text { Logistic regression models CONV } \\
\text { (using conventional clinical assessment } \\
\text { data) and SENSOR (using sensor data } \\
\text { from TUG and overall physical activity) }\end{array}$ \\
\hline [27] & TUG test & $\begin{array}{l}2 \text { inertial sensors ( } 3 D \\
\text { accel and } 3 D \text { gyro) }\end{array}$ & $\begin{array}{l}\text { Anterior of each shin, } \\
\text { shank bone (tibial bone) }\end{array}$ & 52 & $\begin{array}{l}\text { Sequential forward } \\
\text { feature selection }\end{array}$ & $\begin{array}{l}\text { Regularized discriminant classifier } \\
\text { models using } 52 \text { temporal, spatial, } \\
\text { turning, and rotational features } \\
\text { from TUG }\end{array}$ \\
\hline [36] & TUG test & $\begin{array}{l}2 \text { inertial sensors (3D } \\
\text { accel and 3D gyro) }\end{array}$ & $\begin{array}{l}\text { Mid-point of left and right } \\
\text { anterior shank (shin) }\end{array}$ & 44 & Nested CV & $\begin{array}{l}\text { Classification model FRE } \text { combined }_{\text {which }} \\
\text { combines FRE } \\
\text { discrimsor (regularized } \\
\text { parameters during standing walking } \\
\text { and turning) and FRE } \text { clin }_{\text {(logistic }} \\
\text { regression model using clinical data on } \\
\text { fall risk factors }\end{array}$ \\
\hline [49] & TUG test & $\begin{array}{l}2 \text { inertial sensors ( } 3 \mathrm{D} \\
\text { accel and 3D gyro) }\end{array}$ & $\begin{array}{l}\text { Mid-point of left and right } \\
\text { anterior shank (shin) }\end{array}$ & 71 & One-way ANOVA & $\begin{array}{l}\text { FRE }_{\text {combined }} \text { (i.e, the weighted average } \\
\text { of the two FRE models FRE } \\
\text { (regularized discriminant model using } \\
\text { IMU-data from TUG + } \\
\text { anthropomorphic data) and FRE } \text { clinical }_{\text {(logistic regression model using clinical }} \\
\text { questionnaire data) } \\
\text { Each mobility score (speed, turn, } \\
\text { transfers, symmetry, variability) in } \\
\text { mobility impairment score was } \\
\text { significantly associated with } \\
\text { falls history }\end{array}$ \\
\hline
\end{tabular}




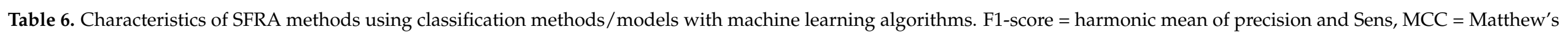
Correlation Coefficient, POM = Proportional odds models.

\begin{tabular}{|c|c|c|c|c|c|c|}
\hline Ref No. & Assessment Task & $\begin{array}{l}\text { No. and Type of } \\
\text { Wearable Sensor(s) }\end{array}$ & Sensor Position(s) & $\begin{array}{l}\text { No. of Sensor } \\
\text { Features }\end{array}$ & Feature Selection Methods & $\begin{array}{l}\text { Methods/Models Able to } \\
\text { Discriminate Significantly between } \\
\text { Fallers/Non-Fallers }\end{array}$ \\
\hline [20] & $25 \mathrm{~m}$ walking & $103 \mathrm{D}$ accel & $\begin{array}{l}\text { Mid-point of } \\
\text { anterior shank }\end{array}$ & 10 & $\begin{array}{l}t \text {-test using Holm correction, } \\
\text { Behrens-Fisher test, forward } \\
\text { wrapper selection } \\
\text { algorithm family }\end{array}$ & RBNC, SVM, KNN, NB \\
\hline [28] & Stair ascent & $13 \mathrm{D}$ accel +1 barometer & $\begin{array}{l}\text { Lower back (belt } \\
\text { around waist) }\end{array}$ & 14 & $\begin{array}{l}\text { Spearman's rank correlations, } \\
\text { Kruskal-Wallis }\end{array}$ & Wavelet DT with adaptive threshold \\
\hline [29] & $\begin{array}{l}\text { Walking } 7.62 \mathrm{~m} \text { under } \\
\text { single and dual tasks }\end{array}$ & $\begin{array}{l}43 \mathrm{D} \text { accel }+2 \text { pressure } \\
\text { sensing insoles }\end{array}$ & $\begin{array}{l}\text { Anterior of each shin, } \\
\text { shank bone (tibial bone) }\end{array}$ & 146 & Acc, F1-score, MCC & SVM, NN, NB \\
\hline [32] & $\begin{array}{l}\text { Identified sit-to-walk } \\
\text { and walk-to-sit } \\
\text { transitions in ADL }\end{array}$ & $\begin{array}{l}1 \text { inertial sensor ( } 3 \mathrm{D} \\
\text { accel data used) }\end{array}$ & Low back (belt) & 72 & $\begin{array}{l}4 \text { machine learning algorithms } \\
\text { in Matlab), linear regression } \\
\text { analysis }\end{array}$ & Ada Boost, SVM, bag, NB \\
\hline [46] & $\begin{array}{l}\text { Battery of } 5 \text { clinical tests } \\
\text { including assessment of } \\
\text { standing balance, } \\
\text { stability, } \\
\text { sit-stand-transitions, } \\
\text { walking, motor function, } \\
\text { reaction, and FoF }\end{array}$ & $\begin{array}{l}5 \text { inertial sensors (3D } \\
\text { accel, 3D gyro and 3D } \\
\text { magnetometer) }\end{array}$ & $\begin{array}{l}\text { Low back, upper and } \\
\text { lower legs }\end{array}$ & 155 & $\begin{array}{l}\text { Two-sample } t \text {-tests, ROC } \\
\text { analysis }\end{array}$ & $\begin{array}{l}\text { Logistic regression, NB, DT, RF, } \\
\mathrm{BT}, \mathrm{SVM}\end{array}$ \\
\hline [51] & $\mathrm{ADL}$ & $\begin{array}{l}13 \mathrm{D} \text { accel }+1 \\
\text { photoelectric heart rate } \\
\text { sensor }\end{array}$ & Wrist & $38^{1}$ & $\begin{array}{l}\text { One-way and two-way } \\
\text { ANOVA, Kruskal-Wallis } \mathrm{H} \\
\text { test, multicollinear test, } \\
\text { recursive feature algorithm in } \\
\text { Caret R package }\end{array}$ & $\begin{array}{l}\text { Three-class classification: } \\
\text { POM and two machine learning } \\
\text { algorithms (DT and RF) } \\
\text { Binary classification: } \\
\text { Three machine learning algorithms } \\
\text { (logistic regression, DT, RF) }\end{array}$ \\
\hline
\end{tabular}




\subsubsection{Sensor Types}

This section provides information on different types of wearable sensors identified in the included articles, differences between article categories, and identified trends in sensor types.

The following sensor types were identified among the included studies (number of articles given in parenthesis): accelerometers (13), gyroscopes (5), a combination of accelerometers and gyroscopes (6), a combination of accelerometers, gyroscopes and magnetometers (3), a combination of accelerometers and barometer (2), a combination of accelerometers, gyroscopes, magnetometers and barometer (1), a combination of a 2D accelerometer and load cell (1), a combination of accelerometers and photoelectric heart rate (1), and a combination of accelerometers and pressure (1).

During 2011-2019, the number of different sensor types used, i.e., their dimensionality, increased after 2016. As shown in Figure A1a (in Appendix B), all articles published during 2011-2015 used one or two different sensor types: accelerometers (7/10 articles), accelerometers and gyroscopes combined $(2 / 10)$, as well as accelerometers and barometers $(1 / 10)$ combined. Starting from 2016, the number of different sensor types has increased: articles published in 2016 used 3D accelerometers ( 3 articles), 3D gyroscope ( 1 article), as well as a combination of a 3D accelerometer and pressure sensor (1 article). During 2017-2019, the number of different sensor types continued to increase, and the dimensionality of the sensor systems increased to 9D (i.e., 3D accelerometers, 3D gyroscopes, 3D magnetometers) and even to $10 \mathrm{D}$ by adding barometer data as well.

The variation in number of different sensor types used was higher among the studies performing discrimination by feature selection (Table 4) than among studies using classification methods/models (Tables 5 and 6). However, the difference was not statistically significant. As shown in Figure A1b (in Appendix B), 1-5 different sensor types were used per publication year among the articles performing discrimination by feature selection. Only 1-2 different sensor types were used per publication year among the studies using classification methods/models with or without machine learning (see Figure A1c in Appendix B). Moreover, the use of 3D accelerometers was higher among the studies performing discrimination by feature selection (see Table 4) than among the studies using classification methods/models (Tables 5 and 6). None of the studies in Tables 5 and 6 that were published during 2017-2019 used 3D accelerometers.

Among the identified studies performing discrimination by feature selection (Table 4), gyroscopes started to be used in 2016. In this period, gyroscopes were used to an equal extent as accelerometers. During 2018-2019, two studies using a combination of accelerometer, gyroscope, and magnetometer features were identified, one of them also combined with barometer features.

\subsubsection{Distribution of Wearable Sensors at Different Body Locations}

This section provides information on how wearable sensors were distributed between body locations, whether there were differences between article categories, as well as trends in distribution.

Starting with the studies performing discrimination by feature selection (i.e., the articles in Table 4), Figure A2 in Appendix B shows that a total of three sensors were used in the two articles from 2011. Two sensors were located on the upper body (pelvis and sternum) and one on the lower body (thigh). In 2013-2014, three articles used a total of four sensors, all located on the upper body (two on the lumbar spine, one on the cervical spine and one on sternum). In 2016, all five articles included sensors located on the upper body (lumbar spine) and one of them also included sensors located on the top of the feet. In 2017, seven articles used a total of nine different sensor body locations. Four of them had sensors located only on the upper body (pelvis, sternum, biceps, wrist, head). Two had sensors located both on the upper and lower body (in [39] at the sternum, lumbar spine, and on the feet, while in [41] on the lumbar spine and one of the ankles) and one [40] positioned the sensors on the shanks/shins. In 2018, all four articles used a sensor located on the upper 
body (three on the lumbar spine and one on the sternum and pelvis). In addition, two of them used sensors located on at least one shin/shank, and one of them used sensors located on the thighs. All three articles published in 2019 also used sensors located on the upper body (lumbar spine). In addition, one of them [50] used a sensor located on one of the heels.

To summarize, $64 \%$ of the wearable sensors used in the studies performing discrimination by feature selection were located on the upper body (Figure 6a). Figure $6 \mathrm{~b}$ shows that the most common body location on the upper body was the lumbar spine (13 sensors). Other upper body locations used more than once include sternum (5), and pelvis (3). Lower body locations used more than once include shin/shank (5), top of foot (4), and thigh (3).

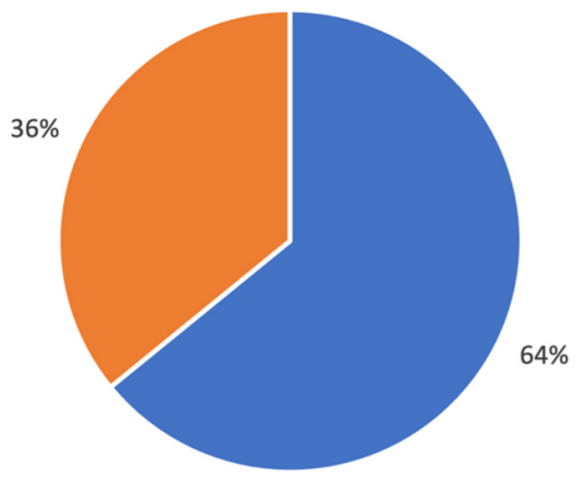

- Upper body = Lower body

(a)

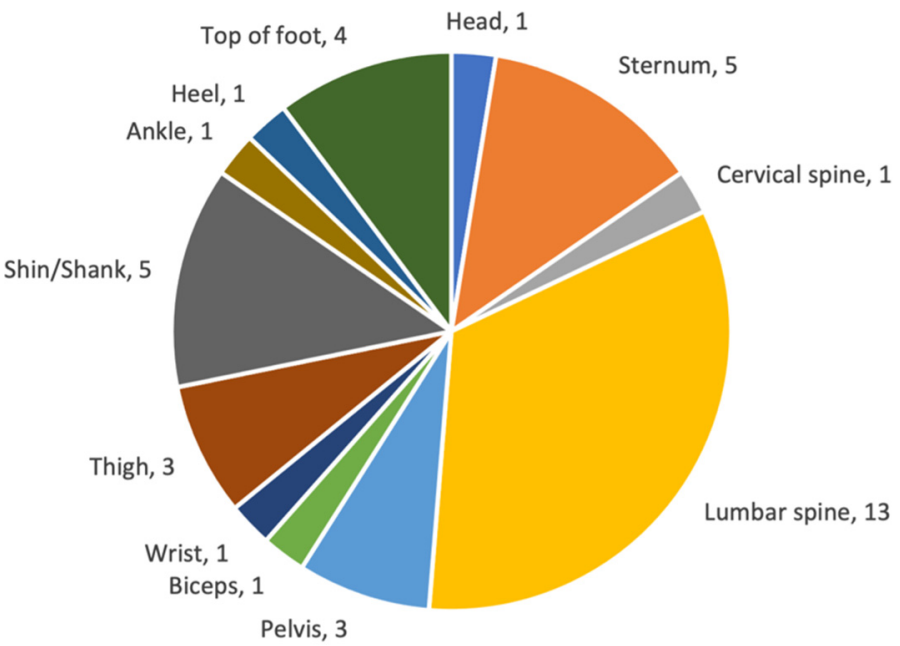

(b)

Figure 6. Information on sensor locations for articles in Table 4, i.e., the articles performing discrimination by feature selection: (a) Distribution of sensors located at the upper or lower body; (b) Number of sensors per body location.

Continuing with the studies using classification methods/models (with or without machine learning algorithms (i.e., the articles in Tables 5 and 6), Figure A3 in Appendix B) shows that most articles reported on sensors located on the lower body with the exception for the publication years 2011 and 2015. However, in 2011, 6/7 of the reported upper body sensors were used in one of the articles where a total of ten sensors were used [20], and only one article was included from 2015. The two articles published in 2014 [27] and 2017 [36] have the same main author and report on the use of sensors located at the shin/shank. The two included articles from 2016 use five different sensor locations, and 6/7 of the sensors were used in one article [29] where most of them were located on the lower body (shins/shanks and under the feet soles), and two of them on the upper body (head and pelvis). The other article from 2016 [32] used a sensor located on the upper body (lumbar spine). Only one article from 2018 [46] used sensors located both on the upper (lumbar spine) and lower body (thighs, and shins/shanks). In 2019, [51] used a sensor combining a $3 \mathrm{D}$ accelerometer and a photoelectric heart rate sensor located on the wrist, while the other study [49] positioned the sensors at the shins/shanks.

To summarize, $61 \%$ of the wearable sensors used in studies using classification methods/models (with or without machine learning (Figure 7a) were located on the lower body. Figure $7 \mathrm{~b}$ shows that the most common body location on the lower body was the shin/shank (12 sensors). Other lower body locations used more than once include thigh (4), under foot (2), and ankle (2). Upper body locations used more than once include lumbar spine (3), wrist (3), biceps (2), and shoulder blade (2). Hence, the body locations used in studies using classification methods/models with or without machine learning, are quite 
different from the body locations used in the studies performing discrimination by features where $64 \%$ of the sensors were located on the upper body.

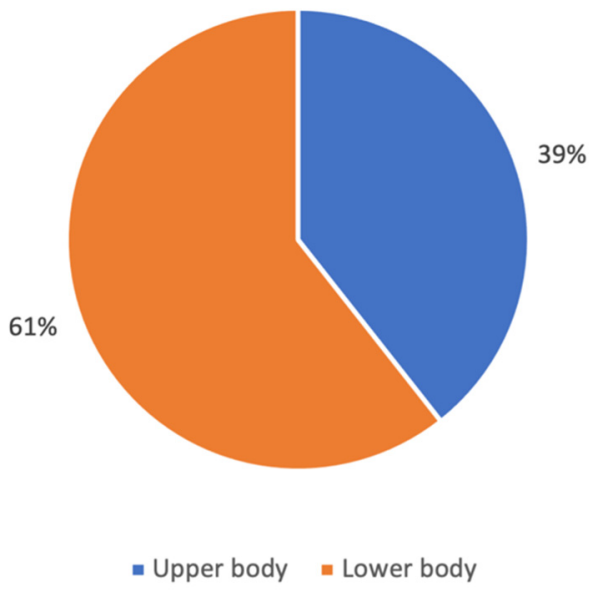

(a)

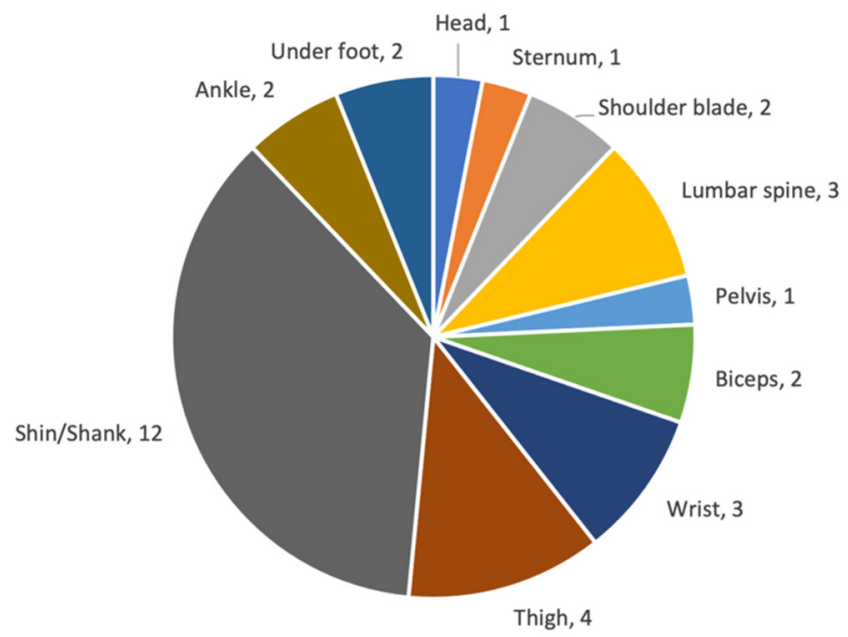

(b)

Figure 7. Information on sensor locations for articles in Tables 5 and 6, i.e., the articles using classification methods/models with or without machine learning algorithms: (a) Distribution of sensors located the upper or lower body; (b) Number of sensors per body location.

\subsection{Signal Processing}

The analysis of methods used for signal/data processing and analysis in the 33 studies identified that the used signal processing approaches could be classified according to three main categories: discrimination by feature selection (22 studies presented in Table 4 ), classification by use of classification methods/models with and without machine learning algorithms (5 studies without machine learning algorithms presented in Table 5, and 6 studies with machine learning algorithms presented in Table 6).

\subsubsection{Sensor Features}

The number of sensor features selected for fall risk assessment analysis (either discrimination or classification) varied from one to hundreds between different studies.

Among studies discriminating by feature selection, i.e., performing statistical analysis directly on selected features (Table 4), most of the studies (14/21) used up to 10 (4-10) sensor features and four studies used 15-21 sensor features [21,34,41,47]. The highest number of sensor features used among the studies was 60 [31]. However, this number differed significantly from the other studies discriminating fall risk by feature selection. Some studies evaluated the discriminatory capabilities of generated sensor features, e.g., Step Stability Index (SSI) [25], Local Dynamic Stability (LDS) [30], and Biometric Signature Trajectory (BST) by [45].

In the studies using classification models without machine learning algorithms (Table 5), three articles from the same main author $[27,36,49]$ used over $40(44-71)$ sensor features in regularized discriminant classifier models. The other two studies [22,23], which both used regression models, utilized 10 and 14 sensor features respectively.

The studies using classification methods/models with machine learning algorithms (Table 6) used more sensor features than studies assessing fall risk based on feature extraction (Table 4) and on classification models without machine learning (Table 5). Two studies [29,46] used approximately 150 sensor features, while two other studies [20,32] used approximately 70 sensor features for four different machine learning algorithms. One study [28], which built on the machine learning classification algorithm decision tree 
(DT), used only seven sensor features. A total of 38 sensor features were combined with 210 variables in Resident Assessment Instrument-Home Care (RAI-HC) and analyzed using machine learning algorithms [51].

\subsubsection{Feature Selection}

All studies employed feature selection, regardless of whether they used statistical analysis directly on the selected features to assess fall risk or used the selected features in classification methods/models which used machine learning algorithms or other types of classifiers.

Most studies used statistical tests in the feature selection process. Some articles stated that the Shapiro-Wilk test had been used to identify whether data was normally distributed prior to feature selection $[43,47,51]$. In studies where the data met requirements for parametric tests, those were used. Here, comparison tests including Analysis of variance (ANOVA) $(10 / 33)$ and $t$-test (9/33) were mostly used. Analysis of co-variance (ANCOVA) was used together with ANOVA in [35] and combined with Multivariate ANCOVA (MANCOVA) in [40]. Moreover, correlation tests using Pearson's correlation were employed in some studies $[22,35,38,39,43]$. When data did not fulfil requirements for parametric tests, nonparametric tests including Wilcoxon-signed-rank [19,25,34,41], Kruskall-Wallis tests [19], $\chi 2$ tests [24,50], Mann-Whitney test [22,25,34,41,42], Friedman test [34,43], Fisher's exact test [41], and Tukey's test [47] were used.

In Table 4, these feature selection methods were mostly used for assessment of individual difference and significance, i.e., which of the features to be included in fall discrimination analysis. However, in Tables 5 and 6 , the methods mostly tended to prepare data for classification models and machine learning algorithms, catering for the prediction and assessment of the classification ability or performance.

\subsubsection{Fall Risk Assessment}

The 22 studies in Table 4 employed selection and comparison of features by performing statistical tests to discriminate between fallers and non-fallers or to classify individuals as fallers or non-fallers. The majority of these articles $(17 / 22)$ compared the features between groups by performing different statistical tests with the aim of identifying features with significant discrimination ability. Some articles $(5 / 22)$ proposed novel or valid measures from sensor measurements and analyzed the feasibility of those, i.e., a novel measure of SSI [25], LDS [30], refined composite multiscale entropy (RCME) and refined multiscale permutation entropies (RMPE) [31], BST [45], and Comprehensive Gait Assessment using Inertial sensor (C-GAITS) score [50].

In total, 11 studies employed classification methods/models with and without machine learning to discriminate between groups with different fall risk or to classify individuals as according to fall risk. Five of those studies (presented in Table 5) employed classification models without machine learning algorithms for fall risk assessment. Most commonly used models were regression models (4 studies) and discriminate classifier models (3). In addition, six studies (presented in Table 6) used machine learning classification algorithms, including adaptive boosting (Ada Boost) (1 study), boosted tree (BT) (1), bootstrap aggregation (bag) (1), DT (3), k-nearest neighbors' classifier (KNN) (1), logistic regression (2), naïve Bayes (NB) (4), neural network (NN) (1), radial basis function network classifier (RBNC) (1), random forest (RF) (2), and support vector machine (SVM) (4) to assess fall risk

\subsection{Identification of Triads and Assessment of Applicability on Classification Methods/Models}

As described in Section 3.1.5, the current review reports on SFRA performed under supervised, semi-supervised, and unsupervised conditions (such as ADL or free-living gait) and the degree of supervision varied between article categories. For example, all studies using classification models without machine learning were supervised while only 
$50 \%$ of the studies using classification methods/models with machine learning algorithms were supervised.

A previous systematic review and meta-analysis of best available evidence of optimal combinations of sensor locations, tasks and feature for fall risk assessment [14] discussed discriminating sensor features of four certain tasks while wearing sensors. The six recommended triads were: (1) angular velocity—walking — chins, (2) frequency-walkinglower back, (3) frequency - walking - upper back, (4) linear acceleration-quiet standinglower back, (4) linear acceleration-quiet standing-lower back, (5) linear accelerationsit-to-stand/stand-to-sit-lower back, and (6) temporal-TUG-shins. The three notrecommended triads were: (1) angular velocity-walking-lower back, (2) frequencywalking—shins, and (3) linear acceleration-walking—shins [14]. In the current review, it was not possible to outline the aforementioned triads for the 11 studies performing classification methods/models, i.e., the studies in Tables 5 and 6. The main reason for this is the fact that they present methods rather than sensor features. Further, the current review identified several assessment tasks that were not included in [14], for example reaction tests, stair ascent and decent, ADL, balance tests in different conditions, and an UEF test. Most of these newer tasks were used in studies performing discrimination by feature selection. Therefore, rather than trying to identify triads like the ones in [14] or counting sensor types/sensor locations for all studies, Sections 3.2.1-3.2.3 present information on number of sensors, sensor types, and sensor locations, differences between article categories as well as trends during 2011-2019. Nevertheless, an analysis relating to the previous systematic review by Montesinos et al.'s triads [14] has been conducted.

Starting with the studies performing discrimination by feature selection (i.e., the studies in Table 4), most sensors were located on the upper body and most of them were located on the lumbar spine. The lower back was included in the triads recommended by [14] for quiet standing and stand-to-sit/sit-to stand tasks but not TUG. For TUG, the recommended triad included temporal-shin. Only the studies $[39,40]$ used TUG as an assessment task, [40] used the recommended sensor location, i.e., the shin. However, none of them presented results that distinguished fallers from non-fallers by using temporal sensor features. Four studies included standing balance tests at different conditions, VR included. Excluding the VR study [38], the three other studies [34,43,48] used sensors located on the lower back or pelvis. Hence, while not being assessment tasks listed in [14], the sensor location mimics the one in the recommended triad (4) above.

Regarding the walking task, [14] identified both recommended and not-recommended triads with respect to the lower back. Eight studies used different walking tasks. These included also walking in different conditions, daily life walking, walking in stairs, 6MWT and $15 \mathrm{~m}$ walking tests. The sensor was located on the lower back in seven studies, and on a nearby location (pelvis) in one study. However, the dimensionality of the collected sensor data varied. In the studies $[19,24,25,31,41,42]$, features from one or more 3D accelerometers were used. A combination of 3D accelerometer and 3D gyroscope features was used in [50], and an even more complex combination (3D accelerometer, 3D gyroscope, 3D magnetometer, and barometer features) was used in [44]. Several of the studies using walking as the assessment task also used more than one sensor but the location of them varied. We note that the triad linear acceleration-walking-lower back was not identified as a recommended triad in [14].

The triad angular velocity-walking-lower back was identified as not-recommended in [14]. Nevertheless, gyroscope features were included in the C-GAITS score [50]. Finally, Table 4 includes two studies [21,30] including the sit-to-stand assessment task. Both used one or more sensors providing 3D accelerometer features. For sit-to-stand, the in recommended triad (4) above includes linear acceleration-lower back. This sensor location was used in [30] but the sensors were positioned on one of the thighs and sternum in [21].

The triads by [14] are not directly applicable for the studies using classification models/methods. The majority of the sensors used in the studies presented in Tables 5 and 6 were located on the lower body with shin/shank being the most common location. Three 
of the studies in Table $5[27,36,49]$ used TUG as the assessment task. All of them positioned the sensors on the shin/shank, i.e., the same location as in the recommended triad (6) above for TUG which included temporal-shins. One study, [22] was conducted by the same research group but used walking as an assessment task with sensors located on the shins/shanks. It should be acknowledged here that although the Shimmer sensor (i.e., a combination of 3D accelerometer and 3D gyroscope features) was used during the assessment, the research has resulted in a commercial quantitative TUG assessment tool called QTUG which is provided by the company Kinesis Health Technology.

One article [23] used both walking and TUG as assessment tasks. The location chosen for a 3D accelerometer was the lower back. Also, this triad was not identified by [14].

None of the recommended triads for walking (1-3 above) include linear acceleration, neither does the recommended triad for TUG (6 above). Hence, the studies in Table 5 show that it is possible to use also other triads when using classification models/methods. The assessment tasks vary significantly between the studies in Table 6, therefore, no further analysis on body locations and identification of triads is provided here.

\subsection{Statistical Analyses on the Sensor-Based Methods' Capabilities to Assess Fall Risk}

Statistical analyses were performed on the SRFA methods' capabilities to assess fall risk, either to discriminate between groups with different fall risk or to classify individuals as faller/non-faller. Methodological data and main findings on discriminatory capabilities of sensor features and classification methods/models are presented in Tables 7 and 8 . Methodological data and classification performance of sensor features, and classification methods/models are presented in Tables 9 and 10.

Table 7. Statistical analyses on the sensor-based features' abilities to discriminate groups with distinct levels of fall risk. BMI = Body Mass Index.

\begin{tabular}{lll} 
Ref No. & $\begin{array}{l}\text { No. of Fallers/No. of } \\
\text { Participants } \\
\text { (Faller/Non-Faller } \\
\text { Labelling Method) }\end{array}$ & $\begin{array}{l}\text { Sensor Features' Performance in Discriminating Groups } \\
\text { with Different Level of Fall Risk (Fallers/Non-Fallers) }\end{array}$ \\
\hline
\end{tabular}

Fallers took significantly longer time to complete sit-stand transitions than non-fallers; Fallers exhibited increased jerk [21] 19/39 (RE-60, CLIN) over the complete assessment than non-fallers; SEF was significantly higher for fallers than non-fallers for the total test, sit-stand-sit components, sit-stand and stand-sit transitions

The SSI was significantly higher for fallers than non-fallers under all three walking conditions (baseline with and without 3, gait harness, obstacle negotiation with harness)

Significantly longer times to regain balance after movement initiation and slower stability time for fallers than for non-fallers.

RE-12: Mean turn duration, mean peek speed of turning and mean number of steps/turn and the coefficient of variance of the turn angle were significantly different between multiple-fallers and non-fallers. Multiple-fallers had a longer turn duration, slower mean peak speed of turning, a higher number of steps/turn, and showed a lower coefficient of variance of turn angle than non-fallers. Multiple-fallers took a significantly higher number of steps/turn and showed a lower coefficient of variance of turn angle than fallers. PRO-6: 7/35 fell during the 6-month period. The coefficient of variance of steps per turn was significantly larger for fallers and multiple-fallers than for non-fallers.
No. of Features and Type of Assessment Task Able to Discriminate Groups with Different Level of Fall Risk (Fallers/Non-Fallers)

6 , sit-stand and stand-sit transitions

RE-12: 4, turning and gait PRO-6: 1, gait 
Table 7. Cont.

\begin{tabular}{|c|c|c|c|}
\hline Ref No. & $\begin{array}{l}\text { No. of Fallers/No. of } \\
\text { Participants } \\
\text { (Faller/Non-Faller } \\
\text { Labelling Method) }\end{array}$ & $\begin{array}{l}\text { Sensor Features' Performance in Discriminating Groups } \\
\text { with Different Level of Fall Risk (Fallers/Non-Fallers) }\end{array}$ & $\begin{array}{l}\text { No. of Features and Type } \\
\text { of Assessment Task Able } \\
\text { to Discriminate Groups } \\
\text { with Different Level of Fall } \\
\text { Risk (Fallers/Non-Fallers) }\end{array}$ \\
\hline [34] & 19/29 (RE-12) & $\begin{array}{l}\text { RMS sway acceleration for ML direction during semi-tandem } \\
\text { stance was significantly higher among fallers than non-fallers. }\end{array}$ & 1 , stability/balance \\
\hline [35] & 33/96 (RE-12) & $\begin{array}{l}\text { After adjusting for demographics, fallers had significantly } \\
\text { lower gait endurance and higher within walk variability in } \\
\text { daily life than non-fallers. }\end{array}$ & 2 , gait \\
\hline [37] & 53/101 (UEF I) & $\begin{array}{l}\text { The UEF index (adjusted for age, gender, BMI, age, discharge } \\
\text { disposition) was a predictor for } 30 \text {-day prospective falls. The } \\
\text { UEF index, which assesses frailty, was higher in the frail } \\
\text { group than in the non-frail group. }\end{array}$ & 1 , upper extremity \\
\hline [38] & 5/13 (CLIN incl. RE) & $\begin{array}{l}\text { People at-risk of falling changed their head tilt in the AP } \\
\text { direction significantly faster than people not at risk. Only } \\
\text { reliable variables (identified from test-retest reliability } \\
\text { evaluations) were included in the analysis. }\end{array}$ & 1 , stability/balance \\
\hline [40] & 16/37 (RE-12) & $\begin{array}{l}\text { Fallers had a significantly higher cadence, higher stride } \\
\text { velocity and shorter stride time than non-fallers. }\end{array}$ & 3 , gait \\
\hline [41] & 11/81 (PRO-12) & $\begin{array}{l}\text { Stair descent rate was significantly higher among } \\
\text { multiple-fallers than non-multiple-fallers }\end{array}$ & 1 , stair negotiation \\
\hline [43] & 10/20 (CLIN incl. RE) & $\begin{array}{l}\text { When vibration was induced in the eyes-closed condition, the } \\
\text { people with a high fall risk changed the local-control } \\
\text { slope } \\
\text { significantly less than people with a low fall risk }\end{array}$ & 1 , stability/balance \\
\hline [44] & $\begin{array}{l}25 / 50 \text { (determined by } \\
\text { clinical partners) }\end{array}$ & $\begin{array}{l}\text { People with a high fall-risk had a significantly shorter walked } \\
\text { distance, lower cadence, lower RMS (vertical acceleration) } \\
\text { and higher stride time than people with a low fall-risk. }\end{array}$ & 4, gait \\
\hline [45] & $22 / 45$ (RE) & $\begin{array}{l}\text { The DTW difference between the reference BST and each } \\
\text { participant's BST was significantly higher among elderly } \\
\text { multiple fallers than non-fallers. }\end{array}$ & 1 , balance/stability \\
\hline [47] & 122/172 (RE-18/RE-6) & $\begin{array}{l}\text { Step velocity variability was significantly lower among older } \\
\text { adult fallers than older adult non-fallers. }\end{array}$ & 1, gait \\
\hline [50] & 65/378 (RE-18) & $\begin{array}{l}\text { Statistically significant lower C-GAITS score among fallers } \\
\text { than non-fallers. }\end{array}$ & 1, gait: \\
\hline
\end{tabular}


Table 8. Statistical analyses on the sensor-based methods' $/$ models' abilities to discriminate groups with distinct levels of fall risk. FRE $=$ Fall Risk Estimate.

\begin{tabular}{ll} 
Ref No. & $\begin{array}{l}\text { No. of Fallers/No. of } \\
\text { Participants } \\
\text { (Faller/Non-Faller } \\
\text { Labelling Method) }\end{array}$ \\
\hline
\end{tabular}

[22]

54/114 (RE-60)

\author{
2 regression algorithms of \\ minimum ground clearance
}

Machine learning algorithms (wavelet DT with adaptive threshold) using barometer and Accel features for classifying stair negotiation

[28] 31/52 (PRO-12)

[49] 1637/6295 (RE-12)

Regularized discriminant model (sensor data), logistic regression model (clinical data)

\section{Classification \\ Models/Algorithms Included in Model Validation Method \\ Discrimination Method}

NA
No. of Features and Type of
Assessment Task Able to

\section{Methods'/Models' Performance in \\ Discriminating Groups with Different Leve \\ of Fall Risk (Fallers/Non-Fallers)}

Discriminate Groups with

Different Level of Fall Risk

(Fallers/Non-Fallers)

Fallers had a significantly lower mean

SagAngVel at mid-swing points, mean

SagAngVel absolute value and min SagAngVel 3, gait

than non-fallers.

Annotated video and 4-fold $\quad$ PRO significantly correlated with reduced stair

$\mathrm{CV}(\mathrm{x} 4$ times) $\quad$ ascent stability (HR-AP, $\mathrm{r}=-0.35)$.
FRE $_{\text {combined }}$ significantly associated with RE (F $=214.19, \rho<0.0001)$. Each mobility score (speed turn, transfers, symmetry, variability) in mobility impairment score was significantly associated with falls history. 


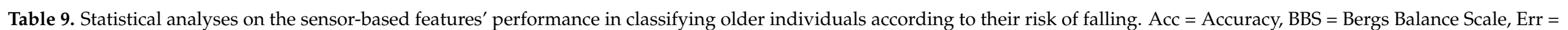
Error, Sens = Sensitivity, Spec $=$ Specificity.

\begin{tabular}{|c|c|c|c|}
\hline Ref No. & $\begin{array}{l}\text { No. of Fallers/No. of Participants } \\
\text { (Faller/Non-Faller Labelling Method) }\end{array}$ & $\begin{array}{l}\text { Sensor Features' Performance in Discriminating Groups with Different } \\
\text { Level of Fall Risk (Fallers/Non-Fallers) }\end{array}$ & Comment \\
\hline [19] & 40/81 (RE-6, CLIN) & $\begin{array}{l}\text { Gait speed }(\text { cut-off } 1.158 \mathrm{~m} / \mathrm{s}): \text { Acc }=77 \% ; \text { Sens }=78 \% \text {; Spec }=78 \% \text {; } \\
\text { AUC }=0.83\end{array}$ & \\
\hline [24] & 16/71 (PRO-12) & $\begin{array}{l}\text { UT HR-VT: } \text { AUC }=0.81(95 \% \text { CI: } 0.69-0.83 ; p<0.001) . \text { Sens }=68.8 \% \text { and } \\
\text { Spec }=84.2 \% \text { at cutoff value } 1.89 \text { based on the Youden index. }\end{array}$ & $\begin{array}{l}95 \% \text { CI for AUC presented (as suggested in } \\
\text { previous reviews) }\end{array}$ \\
\hline [30] & 32/71 (RE-12) & $\begin{array}{l}\text { Kantz' algorithm [53] with the best performing parameter: } \mathrm{AUC}=0.73(95 \% \\
\text { CI:0.60-0.85; } p=0.003) \\
\text { Ihlen's algorithm [52] with the best performing parameter: } \mathrm{AUC}=0.75 \\
\text { (CI:0.60-0.82; } p>0.001) \\
\text { Rosenstein's algorithm [54] with the best performing parameter: } \\
\text { AUC = } 0.59 \text { (CI:0.44-0.71; non-significant) }\end{array}$ & $\begin{array}{l}95 \% \text { CI for AUC of as well as pairwise } \\
\text { comparison of AUC of models presented (as } \\
\text { suggested in previous reviews) }\end{array}$ \\
\hline [31] & 32/71 (RE-12) & 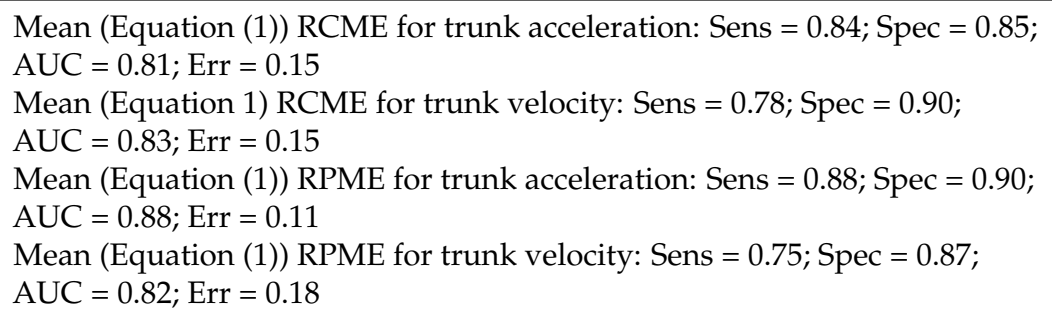 & \\
\hline [39] & 59/148 (RE-12) & $\begin{array}{l}\text { Height, sit-to-stand duration, stand-to-sit duration, turn peak velocity, AP } \\
\text { sway range: Sens }=54.3 \%, \text { Spec }=82.7 \% \text {; max re-scaled } \mathrm{R} 2=0.3244\end{array}$ & \\
\hline [42] & 50/131 (PRO-12) & $\begin{array}{l}\text { Combination of Tinetti balance score, Tinetti total score and ML trunk short } \\
\text { term Lyapunov exponent: AUC }=0.760 \text {, Sens }=0.80, \mathrm{Spec}=0.7 \\
\text { ML trunk short term Lyapunov exponent alone is found insufficient for } \\
\text { distinguishing groups. ML trunk short term Lyapunov exponent comparing } \\
\text { non-fallers and multiple-fallers. AUC }=0.673 \text {; Sens: } 0.53 \text {; Spec: } 0.85\end{array}$ & $\begin{array}{l}\text { Performance metrics for Tinetti scores } \\
\text { presented as suggested in previous reviews. }\end{array}$ \\
\hline [48] & 56/86 (RE-12) & $\begin{array}{l}\text { Standing with feet together sway index: Sens }=78.6 \% \text {; Spec }=75.7 \% \\
\text { AUC }=0.84 \text {; } 95 \% \text { CI: } 0.75-0.92) \\
\text { Standing with one foot in front sway index: Sens }=82.1 \% \text {; Spec }=77.7 \% \text {; } \\
\text { AUC }=0.90 \text { ( } 95 \% \text { CI: } 0.82-0.97)\end{array}$ & $\begin{array}{l}\text { 95\% CIs for all AUCs presented. Performance } \\
\text { metrics of CLIN BBS presented (both aspects } \\
\text { suggested in previous reviews) }\end{array}$ \\
\hline
\end{tabular}




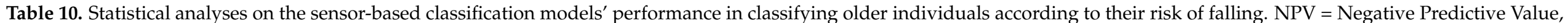
$\mathrm{PPV}=$ Positive Predictive value .

\begin{tabular}{|c|c|c|c|c|c|}
\hline Ref No. & $\begin{array}{l}\text { No. of Fallers/No. of } \\
\text { Participants (Faller/Non-Faller } \\
\text { Labelling Method) }\end{array}$ & $\begin{array}{l}\text { Classification } \\
\text { Models/Algorithms Included in } \\
\text { Discrimination Method }\end{array}$ & Model Validation Method & $\begin{array}{l}\text { Methods'/Models' Performance in Discriminating } \\
\text { Groups with Different Level of Fall Risk } \\
\text { (Fallers/Non-Fallers) }\end{array}$ & Comment \\
\hline [20] & 15/20 (RE-6, CLIN) & $\begin{array}{l}4 \text { machine learning algorithms: } \\
\text { NB, RBNC, KNN, SVM }\end{array}$ & Leave-one-out CV & $\begin{array}{l}\text { NB: Sens }=1 ; \text { Spec }=1 ; \text { Err }=0 \text { for } 4 \text { combinations of } \\
\text { selected features } \\
\text { RBNC: Sens }=1 ; \text { Spec }=0.8 ; \text { Err }=0.05 \text { for } 1 \text { selected feature } \\
\text { KNN: Sens }=0.93 ; \text { Spec }=0.8 ; \text { Err }=0.05 \text { for } 1 \text { selected } \\
\text { feature combination } \\
\text { SVC: Sens }=1 ; \text { Spec }=0 ; \text { Err }=0.25 \text { for } 1 \text { selected } \\
\text { feature combination }\end{array}$ & $\begin{array}{l}\text { Small sample } \\
\text { Very high-performance metrics } \\
\text { (authors conclude that NB } \\
\text { probably is over fitted) }\end{array}$ \\
\hline [27] & $\begin{array}{l}\text { Number of fallers not reported in } \\
\text { RE-60 and PRO-24 data } \\
\text { samples/RE-60: } 909 \\
\text { PRO-24: } 259 \\
\text { Val: } 55 \text { (non-fallers) }\end{array}$ & $\begin{array}{l}\text { Regularized discriminant } \\
\text { classifier algorithms } \\
\text { (Cross-sectional, prospective) }\end{array}$ & $\begin{array}{l}\text { Ten-fold CV (x10 times) and } \\
\text { validation using independent } \\
\text { data set with healthy } \\
\text { control subjects }\end{array}$ & $\begin{array}{l}\text { 1. Ten-fold CV }(\times 10 \text { times }) \\
\text { Cross-sectional model }(\mathrm{RE} \text { dataset }): \text { Acc }=70.02 \% ; \\
\text { Sens }=47.73 \% ; \text { Spec }=84.72 \% ; \mathrm{PPV}=70.14 \% ; \\
\text { NPV }=69.19 \% ; \text { AUC }=0.67 \\
\text { Prospective model }(\text { PRO dataset }): \text { Acc }=76.27 \% ; \\
\text { Sens }=57.20 \% ; \text { Spec }=83.63 \% ; \text { PPV }=59.86 \% ; \\
\text { NPV }=82.54 \% ; \text { AUC }=0.69 \\
2 . \text { Validation using independent datasets with healthy } \\
\text { older adults } \\
\text { Cross-sectional model }(\mathrm{CS} 1+\text { CS2 non-faller }): \\
\text { Acc }=94.11 \% \\
\text { PRO-model }(\mathrm{CS} 1+\mathrm{CS} 2 \text { non-faller }): \text { Acc }=79.38 \%\end{array}$ & $\begin{array}{l}\text { Validation both by CV and by } \\
\text { use of independent datasets (as } \\
\text { suggested in previous reviews) } \\
\text { Validation with independent } \\
\text { dataset: Cross-sectional single } \\
\text { task Acc }>81 \%\end{array}$ \\
\hline [29] & 24/100 (RE-6) & $\begin{array}{l}3 \text { machine learning algorithms: } \\
\text { multi-layer perceptron NN, NB, } \\
\text { SVM }\end{array}$ & $\begin{array}{l}\text { Hold-out method ( } 75 \% \text { training } \\
\text { set and } 25 \% \text { test set). Derived } \\
\text { using either single task data or } \\
\text { dual task data }\end{array}$ & $\begin{array}{l}\text { Best fall risk classification model based on single task i.e., } \\
\text { walk without cognitive load: } \\
4 \text { models with identical performance (SVM degree } \\
2 \text { - using data from insoles-pelvis. SVM degree 3-using } \\
\text { data from insoles-head-pelvis, NN } 9 \text { nodes-using data } \\
\text { from insoles-pelvis, and NN } 20-\text { using data from } \\
\text { insoles-head-pelvis-left shank): Acc = } 84.0 \% \text {; F1-score = } \\
0.600 ; \text { MCC }=0.521 \\
\text { Best fall risk classification model based on dual task (DT), } \\
\text { i.e., walk with cognitive load: } \\
1 \text { SVM degree } 1 \text { model using data from insoles and pelvis: } \\
\text { Acc }=80.0 \% \text {; Sens }=100.0 \% \text {; Spec }=73.7 \% \text {; PPV }=54.5 \% \text {; } \\
\text { NPV }=100.0 \% \text { F } 1=0.706 ; \text { MCC }=0.634 \\
\text { Comparison of } 10 \text { best ST models and } 10 \text { best DT models, } \\
\text { all but one ST model outperformed the DT models. }\end{array}$ & $\begin{array}{l}\text { Hold-out method used for } \\
\text { model validation (preferred } \\
\text { over CV } \\
\text { in [9].) } \\
\text { Single task data models: Best } \\
\text { Acc }>81 \%\end{array}$ \\
\hline
\end{tabular}


Table 10. Cont.

$\begin{array}{lll}\text { Ref No. } & \begin{array}{l}\text { No. of Fallers/No. of } \\ \text { Participants (Faller/Non-Faller }\end{array} & \begin{array}{l}\text { Classification } \\ \text { Models/Algorithms Included in }\end{array} \\ & \text { Model Validation Method }\end{array}$

Labelling Method)
Discrimination Method
Methods'/Models' Performance in Discriminating

Groups with Different Level of Fall Risk

(Fallers/Non-Fallers)

Machine learning algorithms using features from

Daily-Living Transitions:

AdaBoost (mean number of $($ no) features $=18.25$ ):

Acc $=87.90 \%$; Sens $=88.84 \% ;$ Spec $=87.22 \%$

SVM $($ mean no features $=25.50):$ Acc $=90.64 \%$;

Sens $=89.23 \%$; Spec $=91.66 \%$

Bag (mean no features $=10.25)$ : Acc $=87.09 \%$;

Sens $=83.84 \%$; Spec $=89.44 \%$

NB (mean no features $=19.10):$ Acc $=87.74 \%$;

Sens $=78.46 \%$; Spec $=94.44 \%$

Machine learning algorithms using features from

Daily-Living Transitions and functional laboratory tests:

Ada Boost (mean no features $=13.55)$ : Acc $=90.16 \%$;

Sens $=87.50 \%$; Spec $=91.94 \%$

SVM (mean no features $=22.60):$ Acc $=91.00 \%$;

Sens $=88.75 \%$; Spec $=92.50 \%$

Bag (mean no features $=16.05)$ : Acc $=87.16 \%$;

Sens $=85.41 \%$; Spec $=88.33 \%$

NB (mean no features $=15.65)$ : Acc $=90.66 \%$;

Sens $=83.33 \%$; Spec $=95.50 \%$

Machine learning algorithms using features from

functional laboratory tests:

AdaBoost (mean no features $=2.60$ ): Acc $=70.00 \%$;

Sens $=56.66 \%$; Spec $=78.88 \%$

SVM (mean no features $=1.70):$ Acc $=70.66 \%$,

Sens $=42.90 \%$; Spec $=89.16 \%$

Bag (mean no features $=2.60$ ): Acc $=72.50 \%$;

Sens $=68.75 \%$; Spec $=75.00 \%$

NB (mean no features $=2.05$ ): Acc $=70.66 \%$;

Sens $=44.16 \%$; Spec $=88.33 \%$
Authors find that features

extracted from daily life can

distinguish better between

fallers and non-fallers than

features from functional

laboratory tests. The

discrimination was only

slightly improved by

combining the features.

Acc for model using data from

Daily Living transitions $>81 \%$ 
Table 10. Cont.

\begin{tabular}{|c|c|c|c|c|c|}
\hline Ref No. & $\begin{array}{l}\text { No. of Fallers/No. of } \\
\text { Participants (Faller/Non-Faller } \\
\text { Labelling Method) }\end{array}$ & $\begin{array}{l}\text { Classification } \\
\text { Models/Algorithms Included in } \\
\text { Discrimination Method }\end{array}$ & Model Validation Method & $\begin{array}{l}\text { Methods'/Models' Performance in Discriminating } \\
\text { Groups with Different Level of Fall Risk } \\
\text { (Fallers/Non-Fallers) }\end{array}$ & Comment \\
\hline [36] & $11 / 22(\mathrm{RE}-12)$ & $\begin{array}{l}\mathrm{FRE}_{\text {sensor}} \text {-regularized } \\
\text { discriminant model (sensor data) } \\
\text { FRE }_{\text {clin - logistic regression }} \\
\text { model (clinical data) } \\
\text { FRE }_{\text {combined — classifier combined }} \\
\text { theory }\end{array}$ & $\begin{array}{l}\text { Classification performance: } \\
\text { Leave-one out } C V \\
\text { FRE }_{\text {sensor features and model }} \\
\text { selection: Ten-fold CV } \\
(\times 10 \text { times) } \\
\text { Validation of FRE } \mathrm{Fsensor}_{\text {sing }} \\
\text { independent dataset }\end{array}$ & 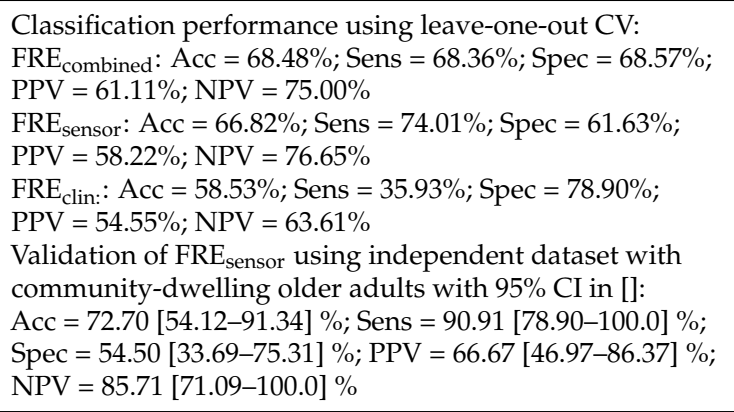 & $\begin{array}{l}\text { Independent validation of } \\
\text { clinical, sensor and combined } \\
\text { FRE classifier models: } \\
\text { FRE }_{\text {sensor model validated on }} \\
\text { independent dataset and } 95 \% \\
\text { CIs for performance metrics } \\
\text { provided (as recommended in } \\
\text { previous reviews) }\end{array}$ \\
\hline [46] & 82/196 (RE-60) & $\begin{array}{l}6 \text { Machine learning algorithms: } \\
\text { SVM, BT, RF, DT, NB, } \\
\text { logistic regression }\end{array}$ & $\begin{array}{l}\text { Ten-fold CV ( } \times 10 \text { times) } \\
\text { Two sample } t \text {-test for } \\
\text { comparing overall } \\
\text { classification Acc. }\end{array}$ & $\begin{array}{l}\text { SVM: Acc }=89.42 \pm 4.82 \% \text {; Sens }=92.67 \pm 6.17 \% ; \\
\text { Spec }=84.90 \pm 8.68 \% \\
\text { BT: Acc }=87.09 \pm 5.56 \% ; \text { Sens }=91.23 \pm 6.71 \% ; \\
\text { Spec }=81.37 \pm 9.37 \% \\
\text { RF: Acc }=86.39 \pm 5.41 \% ; \text { Sens }=92.23 \pm 5.49 \% ; \\
\text { Spec }=78.06 \pm 10.63 \% \\
\text { DT: Acc }=81.64 \pm 6.09 \% ; \text { Sens }=87.25 \pm 7.56 \% ; \\
\text { Spec }=73.29 \pm 10.62 \% \\
\text { NB: Acc }=80.05 \pm 6.11 \% ; \text { Sens }=87.91 \pm 6.60 \% ; \\
\text { Spec }=69.16 \pm 11.80 \%) \\
\text { Logistic regression: Acc }=79.70 \pm 6.37 \% ; \\
\text { Sens }=87.24 \pm 6.75 \% ; \text { Spec }=69.23 \pm 11.94 \%\end{array}$ & $\begin{array}{l}95 \% \text { CIs provided for each } \\
\text { performance metrics (as } \\
\text { recommended in previous } \\
\text { reviews). Two sample } t \text {-tests on } \\
\text { overall classification Acc } \\
\text { showed that a significantly } \\
\text { higher Acc was achieved using } \\
\text { SVM. } \\
\text { Best Acc }>81 \%\end{array}$ \\
\hline
\end{tabular}


Table 10. Cont.

\begin{tabular}{|c|c|c|c|c|c|}
\hline Ref No. & $\begin{array}{l}\text { No. of Fallers/No. of } \\
\text { Participants (Faller/Non-Faller } \\
\text { Labelling Method) }\end{array}$ & $\begin{array}{l}\text { Classification } \\
\text { Models/Algorithms Included in } \\
\text { Discrimination Method }\end{array}$ & Model Validation Method & $\begin{array}{l}\text { Methods'/Models' Performance in Discriminating } \\
\text { Groups with Different Level of Fall Risk } \\
\text { (Fallers/Non-Fallers) }\end{array}$ & Comment \\
\hline [51] & 24/40 (RE-3, non/once/multi) & $\begin{array}{l}\text { Three-class classification model } \\
\text { using features from wearables } \\
\text { and/or RAI-HC: POM, and the } \\
\text { machine learning algorithms DT } \\
\text { and RF } \\
\text { Binary classification model using } \\
\text { features from wearables and/or } \\
\text { RAI-HC: logistic regression, DT } \\
\text { and RF }\end{array}$ & Leave-one-out CV & $\begin{array}{l}\text { 1. Three class classification (non-fallers, fallers, } \\
\text { multiple-fallers): } \\
\text { (a) best performance RF: Acc }=0.838 \pm 0.199 ; \\
\text { Recall }=0.775 \pm 0.233 ; \text { Precision }=0.730 \pm 0.259 ; \\
F_{1}=0.748 \pm 0.248 \\
\text { (b) DT: Acc }=0.757 \pm 0.221 ; \text { Recall }=0.703 \pm 0.254 ; \\
\text { Precision }=0.643 \pm 0.275 ; \mathrm{F}_{1}=0.662 \pm 0.266 \\
\text { (c) worst performance POM: Acc }=0.676 \pm 0.170 ; \\
\text { Recall }=0.626 \pm 0.195 ; \text { Precision }=0.593 \pm 0.195 ; \\
F_{1}=0.584 \pm 0.191 \\
\text { 2. Binary classification (non-fallers + fallers vs. } \\
\text { multiple-fallers): } \\
\text { (a) best performance RF: AUC }=0.894 \pm 0.155 ; \\
\text { Acc }=0.892 \pm 0.160 ; \text { Recall }=0.908 \pm 0.135 ; \\
\text { Precision }=0.928 \pm 0.106 ; \mathrm{F}_{1}=0.888 \pm 0.166 \\
\text { (b) DT: AUC }=0.858 \pm 0.160, \text { Acc }=0.838 \pm 0.200 ; \\
\text { Recall }=0.869 \pm 0.154 ; \text { Precision }=0.851 \pm 0.226 ; \\
F_{1}=0.829 \pm 0.218 \\
\text { (c) worst performance logistic regression: } \\
\text { AUC }=0.838 \pm 0.234 ; \text { Acc }=0.703 \pm 0.172 ; \\
\text { Recall }=0.676 \pm 0.200 ; \text { Precision }=0.657 \pm 0.281 ; \\
F_{1}=0.626 \pm 0.231 \\
3 . \text { Binary classification (non-fallers vs. fallers }+ \\
\text { multiple-fallers): } \\
\text { (a) best performance RF: AUC }=0.865 \pm 0.125 ; \\
\text { Acc }=0.865 \pm 0.132 ; \text { Recall }=0.865 \pm 0.125 ; \\
\text { Precision }=0.908 \pm 0.094 ; \mathrm{F}_{1}=0.853 \pm 0.139 \\
\text { (b) DT: AUC }=0.842 \pm 0.229, \text { Acc }=0.865 \pm 0.192 ; \\
\text { Recall }=0.851 \pm 0.213 ; \text { Precision }=0.886 \pm 0.202 ; \\
F_{1}=0.849 \pm 0.214 \\
\text { (c) worst performance logistic regression: } \\
\text { AUC }=0.743 \pm 0.251 ; \text { Acc }=0.784 \pm 0.224 ; \\
\text { Recall }=0.766 \pm 0.232 ; \text { Precision }=0.778 \pm 0.255 ; \\
F_{1}=0.755 \pm 0.246\end{array}$ & $\begin{array}{l}95 \% \text { CI provided for each } \\
\text { performance metrics (as } \\
\text { recommended in previous } \\
\text { reviews). Pruning used in } \\
\text { training of DT models to avoid } \\
\text { overfitting. } \\
\text { Acc }>81 \%\end{array}$ \\
\hline
\end{tabular}




\subsubsection{Capability in Discriminating Groups with Varied Level of Fall Risk}

Eighteen (18/33) studies analyzed the SFRA methods' capabilities to discriminate between groups of older adults with different fall risk, mostly fallers/non-fallers. Most of them (15/33, see Table 7) evaluated the discriminative capability of sensor features and a few $(3 / 33$, see Table 8$)$ evaluated the discriminative capability of classification methods/models.

The 15 studies evaluating capabilities of sensor features to discriminate between groups (presented in Table 7) included 5-122 fallers (mean 31, median 20.5, SD 28). Only 2/15 studies identified fallers based on PRO data, one for 12 months and one for 6 months. Each study identified 1-6 sensor features which differed significantly between groups of participants with different fall risk levels. Almost half (7/15) of the studies identified sensor features related to gait, both more complex measures $[25,50]$ and specific gait characteristic features such as within walk variability [35]. Moreover, one study identified that stair descent rate significantly differed between multiple- and non-multiple-fallers [41]. Five studies identified that features related to balance were significantly different between groups, for example during tandem stand [34], in regain of balance after movement initiation [26] and upon external stimuli [43].

The three studies evaluating the capabilities of classification models/algorithms to discriminate between groups (presented in Table 8) included 31-1637 fallers (mean 574, median 54, SD 752). One of the studies used an exceptionally large sample to validate a model that had been previously reported [49]. One of the studies [28] identified fallers based on PRO data, and a period of 12 months was used. Both classification methods/models with [28] and without $[22,49]$ machine learning were evaluated. Two of the articles stated that model validation was performed.

\subsubsection{Capability in Classifying Individuals as Fallers/Non-Fallers (or Equivalent)}

Fifteen (15/33) studies analyzed the SFRA methods' performance in classifying older adults as fallers/non-fallers or equivalent. Seven of them evaluated classification performance of sensor features directly (Table 9) and eight evaluated classification methods/models which used sensor derived features (Table 10).

The seven studies evaluating performance of sensor features to classify individuals (presented in Table 9) included 16-50 fallers (mean 41, median 40, SD 14). Only two of them identified fallers based on PRO data, both for 12 months. Some studies analyzed features selected from sensor signals, e.g., gait speed [19] or HR derived from upper trunk accelerometry [24]. Others analyzed generated features, e.g., SSI [25], LDS [30], RCME, and RMPE [31].

Six (6/7) studies reported Area Under Curve (Operating Characteristics-curve) (AUC)values (range $0.67-0.90$ ), half of them reported $95 \%$ confidence intervals (CIs) of the average AUCs and four of them reported AUC-values of 0.81 and higher. These six studies also reported values of sensitivity, i.e., the probability of classifying a true faller as faller, (range $53-88 \%$ ) and specificity, i.e., the probability of classifying a true non-faller as non-faller (range 72-90\%). As shown in Figure 8,5/6 of these studies reported a specificity that was at least as high as the sensitivity. This indicates that the methods' performance in classifying non-fallers was as least as high as their performance in classifying fallers. For example, ref $[39,42]$ reported sensitivity values of $53 \%$ and $54.3 \%$, respectively (see values marked with (1) and (2) in Figure 8). Ihlen et al. [31] reported the highest sensitivity $(88 \%$, see value marked with (3) in Figure 8). 


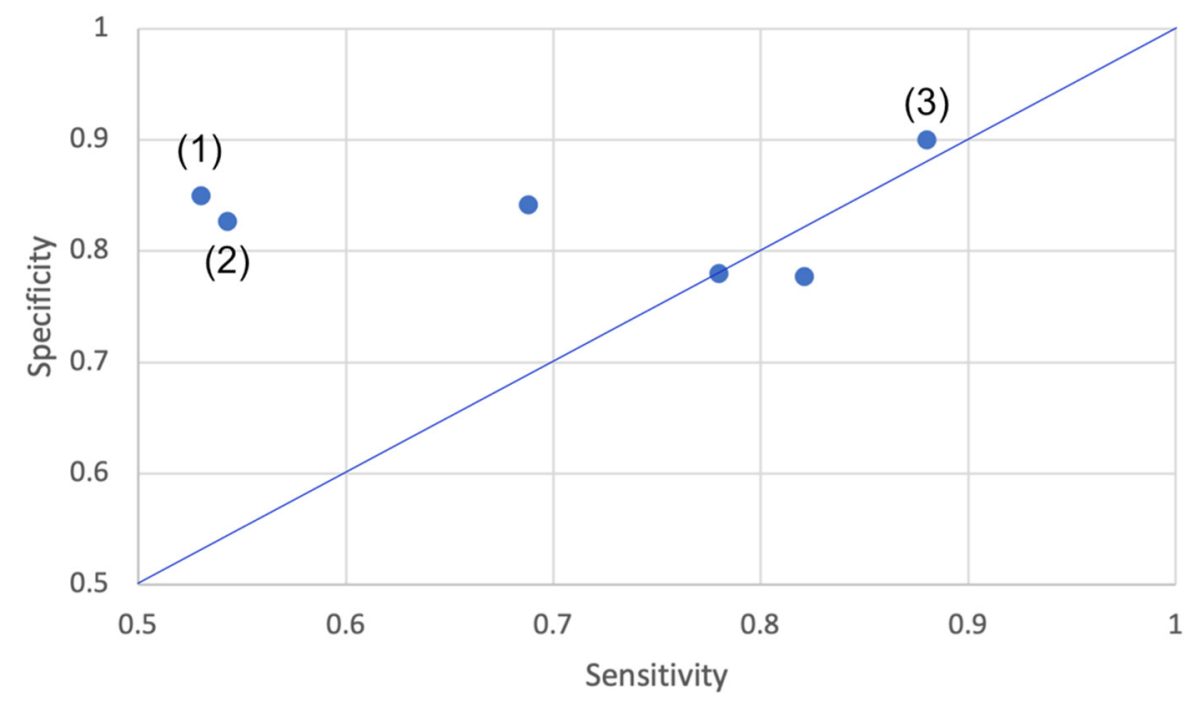

Figure 8. Specificity versus Sensitivity for studies reporting classification performance of sensor derived features. The blue line indicates specificity = sensitivity. (1), (2), and (3) denote values from [46], [44] and [37], respectively.

Eight studies evaluated classification performance of sensor-based classification methods/models. One of them did not report on number of fallers in their sample but the other seven studies, presented in Table 10, included 11-33 fallers (mean 21, median 22, SD 7), all identified based on RE data.

Type of metrics used to report on classification performance varied between studies: most studies $(7 / 8)$ reported classification accuracy with best performance values in the range $70-91 \%$. In addition, values on sensitivity (best values of studies in range $36-100 \%$ ), specificity (best value of studies in range 55-100\%) and AUC-values (best value of studies in range $0.67-0.93$ ) were reported. Three of the eight studies presented CIs for the reported values and three studies $[23,42,48]$ reported performance metrics of clinical fall risk assessment methods for comparison.

More than $60 \%$ of the studies (5/8) evaluated the performance of models using machine learning algorithms. Each study evaluated the performance of three to six models such as NB, SVM, and multi-layer perceptron NN. Three of the four studies that included SVM-based models in their comparisons identified that this type of machine learning algorithm resulted in the best performance $[29,32,46]$. The remaining $40 \%$ of the studies (3/8) evaluated classification models based on logistic regression algorithms [23] and regularized discriminant classifier algorithms [27,36].

Accuracy values reported from studies using classification models with machine learning (79.7-91\%) were higher than accuracy values reported from studies that used classification models without machine learning (70-72.7\%) (see Table 10). It should be noted though that only the highest achieved accuracy value per classification model is reported in this review. Moreover, studies employing models with machine learning reported higher sensitivity and specificity values compared to classification methods/models using other types of classifiers (see Figure 9). Here, the lowest sensitivity value, presented by [27], was below $50 \%$ (see data point marked with double asterisks in Figure 9). However, the study by Caby et al. [20], which compared four different machine learning algorithms, reported sensitivity values of 0 and 1 (see data points marked with one asterisk in Figure 9). 


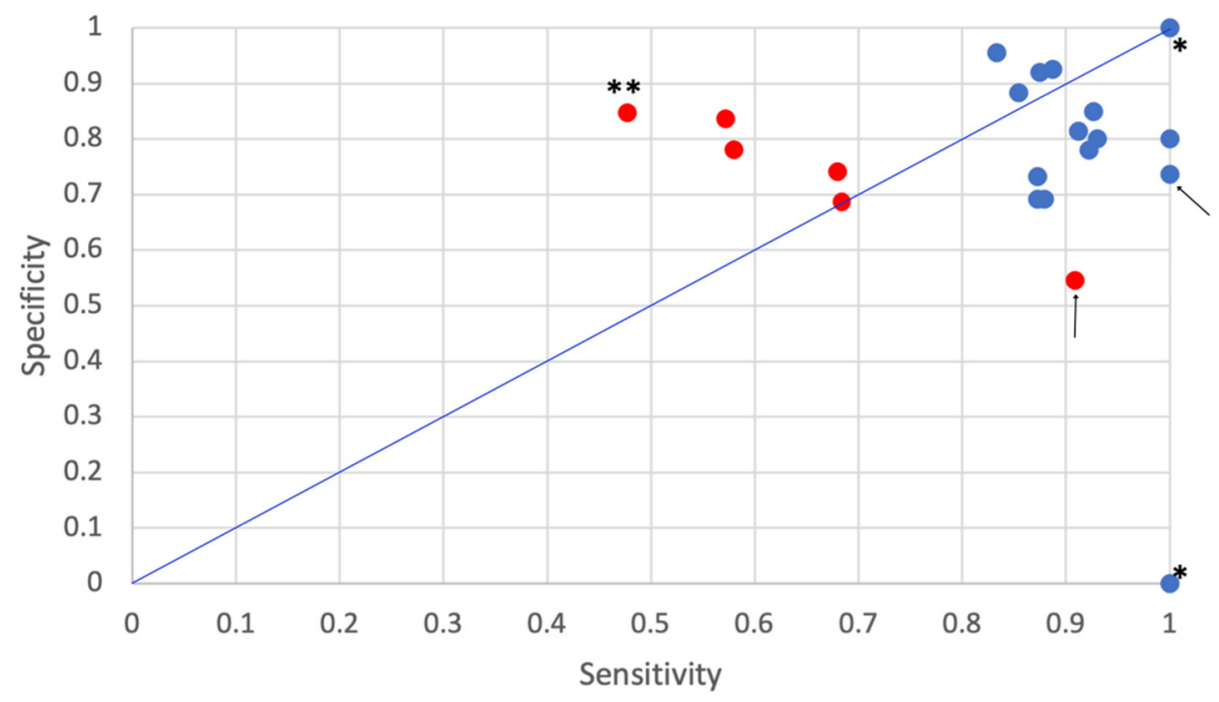

Figure 9. Specificity versus Sensitivity from studies using classification methods/models (presented in Table 10). Data from studies using models with machine learning are represented by blue dots and data from studies using models without machine learning are represented by red dots. The blue line indicates specificity = sensitivity. Data from evaluations using methods other than CV (hold-out or independent dataset) are marked with arrows. Two data points from [29] are marked with asterisks and one data point from [41] is marked with double asterisks.

All studies validated their classification models, mostly by cross validation (CV). However, one study used a hold-out method with $75 \%$ of the data in the training set and $25 \%$ in the validation set [29], and one study used an independent dataset for model validation [36]. In both cases, the reported specificity was lower than the sensitivity (see data points marked with arrows in Figure 9), and this indicated that their performance in classifying fallers were at least as high as their performance in classifying non-fallers. Moreover, one of the studies which used CV reported that pruning was used in the model training to avoid overfitting [51].

\section{Discussion}

This article presents a systematic review of evaluations of SFRA methods in peer reviewed literature published 2010-2020. A total of 389 publications were screened for eligibility and 33 articles were included in the final assessment.

The current review identified that the most studied population was communitydwelling older adults. Although sample sizes varied widely between studies, 33\% (12/35) of the samples in the 33 included studies had at least 100 participants. This percentage was higher than what had been identified in the review by Rucco et al. [15] which reported that only $10 \%(4 / 42)$ of their included studies had more than 100 participants. The review by Shany et al. [7] pointed out the need for high-quality validations of concepts that had been established as proof-of-concept in previous research. The current review identified one example of a large-scale validation published in 2019 [49] with a sample of 6295 participants.

RE data was identified as the most used comparator in the included studies. This result is in accordance with previous reviews which have identified RE data alone [14] or in combination with CLIN data $[8,9,13]$ as the most common methods for generating outcomes to compare SFRAs. Although the need for using PRO data has been emphasized in previous reviews [7-9,13], and that a positive trend of increased use of PRO data was identified by Shany et al. [9], the current review could not identify an increase in prospective studies over the publication period. 
The proportion of fallers (or equivalent outcomes indicating increased fall risk) in study samples varied between 14 and $71 \%$ with an average of $44 \%$. The same range was reported in [15]. However, thresholds used to define a person with increased fall risk (at least one or two falls) varied. Most of the included studies based the SFRA on supervised assessment tasks. This is positive with regards to the need for research to support supervised SFRA and not only focus on unsupervised SFRA which was described in [7].

The number of different sensor types used in the included articles increased over time: while only 1-2 sensor types were used in the 10 articles published during 2011-2015, the number of sensor types increased from 2016. A higher number of sensor types was used among studies performing discrimination by feature selection than by those using classification methods/models. Moreover, the accelerometer, commonly used according to Bet et al. [16], was not used at all in the studies using classification methods/models that were published during 2017-2019.

This review identified that studies performing discrimination by feature selection and studies using classification methods/models differed in sensor locations used: while studies using classification methods/models mostly used sensors located on the lower body (shin/shank was the most common location), studies using feature selection mostly used sensors on the upper body (lumbar spine was the most common position). Another review by Bet et al. [16] also analyzed sensor locations and found that the most common location was the waist ( 8 articles), followed by the lumbar region (7), ankle (4), pelvis (4), and head (3). It is worth noticing here that different terminologies may possibly be used to denote the same sensor location. For example, [14] identified recommended and not-recommended triads including the shins but lists no articles including features from the ankle, while [16] identified four articles with sensors located on the ankle but none on the shin. Further, while [16] reported that the most frequently used locations were the waist and lower back (lumbar spine), [14] stated that the most common placement was the lower back (approximately L3). In addition, Rucco et al. [15] used the notation trunk for sensors located at L3, L5, sternum, waist, pelvis, neck, and chest. Hence, a direct comparison of results obtained in this review with results from the previous reviews is not straightforward.

The review by Sun and Sosnoff [13] focused on four major sensing technologies (inertial sensors, video/depth camera, pressure sensing platform and laser sensing) for SFRA in older adults. The authors presented outcome measures related to different assessment tasks (steady state walking, TUG test, standing postural sway, and dynamic tests) [13]. Howcroft et al.'s review [8] focused solely on inertial sensors. The current review included studies using wearable or mobile inertial sensors used to characterize movements by extracting features from sensor signals. Hence, the range of sensors used in the included studies was more limited in this review compared to the range reported in [13] but somewhat broader than the range reported in [8].

In accordance with the review by Shany et al. (2015) [9], selected features, methods for selecting/extracting them, as well as the number of features incorporated into each model varied substantially between studies. Shany et al. presented both numbers of features subjected to analysis and numbers of sensor features. In addition, they highlighted uncertainty of numbers by using the symbol "?" [9].

Montesinos et al. [14] identified strong/very strong associations between fall risk assessment outcomes and nine triads (combinations of a feature category, a task, and a sensor placement). In the current review, it was not possible to outline triads for the 11 studies performing fall risk assessment using classification methods/models. Further, several assessment tasks not included in Montesinos et al.'s [14] analysis were identified in the current review. Most of these newer tasks were used in studies performing discrimination by feature selection. Rather than trying to identify triads like the ones outlined by Montesinos et al. [14] or counting sensor types/sensor locations for all studies, the current review has instead presented information on sensor locations and sensor types 
used for studies performing discrimination by feature selection and classification methods/ models, respectively.

Previous reviews have categorized SFRA signal processing methods differently compared to this review. For example, Howcroft et al. [8] claimed that regression models were employed to predict fall risk in $65 \%$ of their included studies. Other methods employed were mathematical classifiers (25\%), DT (15\%), NN (15\%), SVM $(10 \%)$, and cluster analysis $(10 \%)$. Some of the studies $(30 \%)$ employed more than one method. In addition, Sun and Sosnoff [13] presented a diverse collection of quantitative models/methods including logistic regression, linear regression, RBNC, SVM, NB, multi-layer perceptron NN, Locally Weighted Learning, DT, Cluster analysis, kNN, NN, neuro evolution of augmenting topologies (NEAT), and discriminate analysis employed to predict fall risk [13]. Both mentioned reviews categorized regression model as a classification method [8,13]. On the contrary, Bet et al. [16] used two main categories of data processing (feature extraction and machine learning techniques) in their analysis of included articles. They classified only data processing methods that carried out fall risk assessment by feature comparisons using statistical tests as "feature extraction" [16]. Notably, the current review categorized signal processing methods based on both the type of methods and on the results that the methods produced. In Table 4, seven articles employed logistic regression, i.e., logistic regression [41]; logistic regression and ROC curve [42]; logistic regression and ANOVA regression [37]; stepwise logistic regression [39]; stepwise logistic regression and ROC curve [19,24]; and univariate logistic regression [30]. In these articles, logistic regressions are used with the purpose to identify individual significant features associated with fall risk but not directly for classification. Therefore, these signal processing methods are categorized as "feature selection" in this review. Moreover, single linear regression, which was employed only in one article to assess the correlation between C-GAITS score and walking speed [50], was not characterized as a classification method. In Table 5, four articles employed logistic regression as a classification model [22,23,36,49]. These articles developed classification models based on regression models with related data. Moreover, in Table 6, a logistic regression model was employed as a machine learning classification model in one article by Yang et al. [51].

The included studies evaluated either the SFRA methods' capabilities to discriminate groups of older adults with different fall risk ( $55 \%$ of the studies) or their performance in classifying individuals according to fall risk ( $45 \%$ of the studies). The SFRA methods were either using sensor features or classification methods/models (with and without machine learning) for discrimination/classification. This review identified a large number of sensor features ( $47 \%$ of them related to gait) and three classification models were identified to differ significantly between groups with different fall risk levels. Moreover, the review identified that classification performance was mainly reported using accuracy (highest values per feature/model 70-91\%), sensitivity (highest values per feature/model 36-100\%), specificity (highest values per feature/model 55-100\%) and AUC (highest values per feature/model 0.67-0.93). The review by Sun and Sosnoff [13] presented data on full ranges of accuracy, sensitivity and specificity reported in their included articles while the current review only reported the highest values identified for each of the evaluated SFRA methods. Moreover, the review by Sun and Sosnoff [13] and the current review had only four studies $[19,20,23,24]$ in common. Hence, Sun and Sosnoff [13] present lower values in the minima of ranges for accuracy, sensitivity and specificity than the current review. In general, the methods' Specificity (performance in classifying non-fallers) was higher that their Sensitivity (performance in classifying fallers) in the current review. In accordance with the previously identified need to compare accuracies of SFRA methods with accuracy of CLIN data [8], the current review identified three studies $[23,42,48]$ that reported performance metrics of clinical fall risk assessment methods for comparison. 
Howcroft et al. [8] have previously pointed out that the reported accuracy values exceed the theoretical maximal accuracy (81\%) for SFRA prediction of at least 1 fall in the upcoming year calculated by [10]) and concluded that prediction performance is overestimated in current literature, mainly due to small samples, large feature pools, model overfitting, lack of validation, and misuse of modelling techniques. The current review identified one study which reported an idealistic model performance (Error $=0$, Sensitivity $=1$, Specificity $=1)[20]$ and five studies that reported model classification accuracy values exceeding $81 \%$ [27,29,32,46,51]. All these studies, except [27], used machine learning algorithms. The current review identified that all the studies presenting fall risk classification performance also reported on model validation methods. Although $\mathrm{CV}$ was used in most cases, one study performing validation with an independent sample [36] was also identified. This is a validation method that has been recommended by [9]. In addition, one example of the hold-out method was identified, data from 75 participants was included in a training set and data from 25 participants was used in a test set [29]. The identified use of model validation among the included studies in the current review is higher than the levels identified by Sun and Sosnoff [13]. Only 50\% of their included studies had applied the recommended model validation techniques (including leave-one-out CV, ten-fold CV, 0.632 bootstrap technique and hold-out method).

\section{Conclusions}

This review identified evidence of SFRA, both in terms of discriminative capacity and classification performance:

(1) A large number of sensor features (almost 50\% related to gait) and three classification (one with machine learning) models using sensor features (related to gait and stair descent) differed significantly between groups of older adults with different fall risk level.

(2) Six studies reported on sensor features (1-5 features per study, in one study combined with the Tinetti balance score) being able to classify individuals as fallers/nonfallers (or equivalent) with AUCs of at least 0.75. Five of these six studies used only 3D accelerometers and one used only gyroscope data. Assessment tasks monitored were walking ( $4 / 6$ studies), TUG test $(1 / 6)$, and standing balance $(1 / 6)$.

(3) Seven studies reported on classification models (four with machine learning and three without) being able to classify individuals as fallers/non-fallers (or equivalent) with accuracies of at least $84 \%$ and/or AUCs of at least 0.74 . All these studies used accelerometers, either alone (1 study) or in combination with $1-5$ other sensors including gyroscopes (4 studies), magnetometers (1), pressure sensors (1) and heart rate sensor (1). The number of sensor features analyzed in these studies ranged between 38 and 155. Although more than half of the studies (4/7) used clinical tests (mainly TUG test) as assessment task, ADL (2 studies) and walking (1) were also used.

However, the review also identified several factors previously reported to increase risk of bias $[7-9,12-16]$ :

(1) The use of prospective study design was limited among the included studies and no positive trend over the publication period could be identified. Two thirds of the included studies used cross-sectional design with RE and/or CLIN data as outcomes to compare SFRA with. Potential sources of biases associated with RE data include limited accuracy of recall of falls in the elderly [55] and risk of altered motion patterns due to history of falls [9]. Moreover, clinical assessments can introduce study bias since they are often assessed subjectively and do not achieve $100 \%$ clinical accuracies $[7,13]$. 
(2) Approximately one third (12/35) of the samples in the included studies had at least 100 participants. Although this proportion was higher than the $10 \%$ identified in [15], this indicated that most of the included samples were limited. Inadequate sample size has been identified as an important risk of bias in SFRA research [9]. Moreover, $14-71 \%$ (44\% in average) of the participants in the included samples had elevated fall risk (i.e., were labelled as fallers, frail, at risk, etc.), the same range was reported in [15]. Insufficient raw numbers of events can contribute to small-sample bias [56] and samples with very few fall events relative to the total sample size can lead to distorted models [9,57]. Our comparison of sensitivity and specificity identified that the SFRA methods' performance in classifying non-fallers (or persons not at risk) was at least as high as their performance in classifying fallers (or percentage). This might be a consequence of low in-sample proportions of persons with elevated fall risk.

(3) Low consensus was identified among the included studies in number and type of sensor features used in SFRA. Moreover, the number of features was highest among studies using classification models with machine learning. This result illustrated that the previously highlighted "curse of dimensionality" remains a challenge in the model selection process of SFRA which might contribute to sample bias [9].

(4) Although all included studies using classification models performed model validation, the most common validation method was $\mathrm{CV}$ which has been identified to increase the risk of bias in estimated performance [9], especially for small data sets [58]. However, this review also identified model validation using independent datasets [23] and hold-out technique [29] which, according to [9], are preferred over CV.

Hence, future SFRA research should continue to reduce risk of bias by further implementing methodological improvements.

\section{Limitations}

The search terms used, specifically the required combination of "risk" and "assessment" may have limited the search results of this review. However, the number of articles included in the current review $(n=33)$ is in the same range as previous reviews $(n=22$ in [13], $n=40$ in [8], $n=24$ in [9], $n=13$ in [14], $n=42$ in [15] and $n=29$ in [16]). Interestingly, only $9 / 33$ of the included studies $[19-25,27,41]$ overlapped with previous reviews.

Author Contributions: Conceptualization and methodology: A.K. and M.E.; investigation, data curation, writing (original draft and review/editing): A.K., J.D. and M.E. All authors have read and agreed to the published version of the manuscript.

Funding: This research was conducted within the scope the ESS-H+ (Embedded Sensor Systems for Health Plus). The project is funded by the Swedish Knowledge Foundation (Project Number 20180158) and the project partners (including Mälardalen University and Motion Control).

Institutional Review Board Statement: Not applicable.

Informed Consent Statement: Not applicable.

Data Availability Statement: Not applicable.

Acknowledgments: The authors are grateful to Niklas Persson for his contributions in the literature searches conducted in 2019.

Conflicts of Interest: The authors declare no conflict of interest. The funders had no role in the design of the study; in the collection, analyses, or interpretation of data; in the writing of the manuscript, or in the decision to publish the results. 


\section{Abbreviations}

The following abbreviations have been used in the article:

Acc

accel

Ada boost

ADL

ANOVA

ANCOVA

$\mathrm{AP}$

AUC

Bag

BBS

BMI

BST

BT

C-GAITS

CI

CLIN

COG

$\mathrm{CS}$

$\mathrm{CV}$

DT

DTW

EM

Err

F1-score

FoF

FRE

FTSS

GMM

gyro

HR

ICC

IMF

KNN

LDS

MANCOVA

MCC

MGC

ML
Accuracy

Accelerometer

Adaptive boosting

Activity in daily life

Analysis of variance

Analysis of co-variance

Anterior-posterior

Area Under Curve

(Operating Characteristics-curve)

Bootstrap aggregation

Bergs Balance Scale

Body Mass Index

Biometric Signature Trajectory

Boosted tree

Comprehensive Gait

Assessment using Inertial sensor

Confidence intervals

Clinical assessment methods

Center of gravity

Cross-sectional

Cross validation

Decision tree

Dynamic Time Warping

Expectation Maximization

Error

Harmonic mean of precision and Sens

Fear of Falling

Fall risk estimate

5 times Sit-to-stand test

Gaussian Mixture Models

Gyroscope

Harmonic Ratio

Intra-class correlation coefficient

Intrinsic Mode Function

$\mathrm{K}$-nearest neighbor

Local Dynamic Stability

Multivariate ANCOVA

Matthew's Correlation Coefficient

Minimum ground clearance

Medio-lateral
MML Minimum Message Length

NEAT Neuro evolution of augmenting topologies

NB Naïve Bayes(ian)

NN Neural networks

NPV Negative Predictive Value

PLS-DA Partial least square discriminatory analysis

POM Proportional odds models

PPV Positive Predictive Value

PRO Prospective falls occurrence

(followed number indicating period in months for prospective falls occurrence)

QTUG Quantitative TUG (a commercial tool)

RAI-HC Resident Assessment Instrument-Home care

RBNC Radial basis function network classifier

RCME Refined composite multiscale entropy

RE Retrospective falls history

(followed number indicating time period

in months for falls history)

RF Random forest

RMPE Refined multiscale permutation entropies

RMS Root Mean Square

ROC Receiver operating characteristic

SagAngVel Angular velocity in the sagittal plane

SD Standard Deviation

SEF Spectral Edge Frequency

SEMI-SUP Semi-supervised

Sens Sensitivity

SFRA Sensor-based fall risk assessment

6MWT Six-Minutes Walking Test

Spec Specificity

SSI Step Stability Index

SSQ Simulator Sickness Questionnaire

SUP Supervised

SVM Support vector machine

TUG Timed Up and Go

UEF Upper extremities' function

UNSUP Unsupervised

UT Upper trunk

Val Validation

VR Virtual reality

VRHMD VR head-mounted display

VT Vertical 


\section{Appendix A}

The appendix provides details to text provided in Section 2.3 Data Extraction.

Table A1. Template for data extraction.

\begin{tabular}{ll}
\hline Variables & Type of Collected Data \\
\hline 1. First author & Free text \\
\hline 2. Title & Free text \\
\hline 3. Journal & Free text \\
\hline 4. Publication year & $2010-2020$ \\
\hline 5. Population of older people in sample & $\begin{array}{l}\text { Patients/Community-dwelling/Residential home } \\
\text { (or similar)/Other }\end{array}$ \\
\hline 6. Faller/non-faller labelling method & RE and/or PRO and/or CLIN or other. \\
& $\begin{array}{l}\text { For CLIN and PRO, the number of months used for } \\
\text { collection of RE and PRO was collected. }\end{array}$ \\
\hline 7. Number of participants 60 years in sample & Number \\
\hline 8. Proportion of single fallers in sample & Percentage (0-100\%) \\
\hline 9. Proportion of multiple fallers in sample & Percentage (0-100\%) \\
\hline 10. Assessment task monitored by wearable sensors & Free text \\
\hline 11. Degree of supervision during task & SUP/SEMI-SUP/UNSUP \\
\hline 12. Number of wearable sensors & Number \\
\hline 13. Type of wearable sensors & Free text \\
\hline 14. Wearable sensor position(s) & Free text \\
\hline 15. Number of sensor features & Number \\
\hline 16. Feature selection methods & Free text \\
\hline 17. Signal & \\
\hline
\end{tabular}

17. Signal processing methods used to discriminate/classify older adults according to fall risk
(a) Wearable sensor features or
(a) Free text or
(b) Models/algorithms able to discriminate significantly between fallers/non-fallers with
machine learning
(b) Free text or
(c) Free text

(c) Models/algorithms able to discriminate significantly between fallers/non-fallers without machine learning

18. Number of fallers/number of participants $\quad$ Number/Number

19. Discrimination/classification performance, either

(a) Sensor features' performance in discriminating groups with different level of fall risk

(fallers/non-fallers)

(b) Methods' /model's performance in discriminating groups with different level of fall risk

(fallers/non-fallers)

(c) Sensor features' performance metrics in classifying individuals as fallers/non-fallers.

(a) and (b) Free text

Only the highest performance metrics are reported.

(d) Model's performance metrics in classifying individuals as fallers/non-fallers. Only the highest performance metrics for each model are reported.

20. For studies using classification methods/models (performance extracted in $19 \mathrm{~b}$ and d):

(a) Classification models/algorithms included in discrimination method

(b) Model validation method

Free text (if used)

(c) Comments (of study methodology in relation to recommendations of previous review)

21. For studies analyzing discriminatory performance (performance extracted in 19 (a)-(b): Number and type of features able to discriminate groups with different level of fall risk (fallers/non-fallers) 


\section{Appendix B}

This appendix provides complimentary graphs to the information provided in Section 3.2.

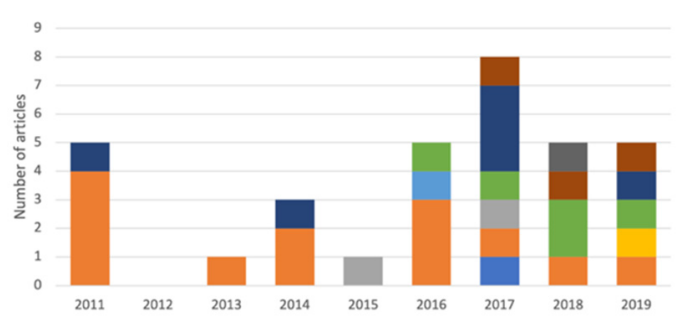

(a)

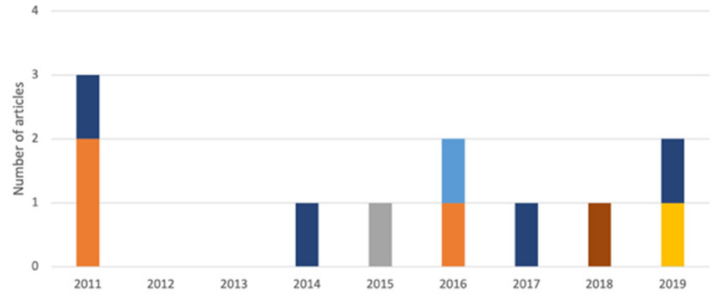

(c)

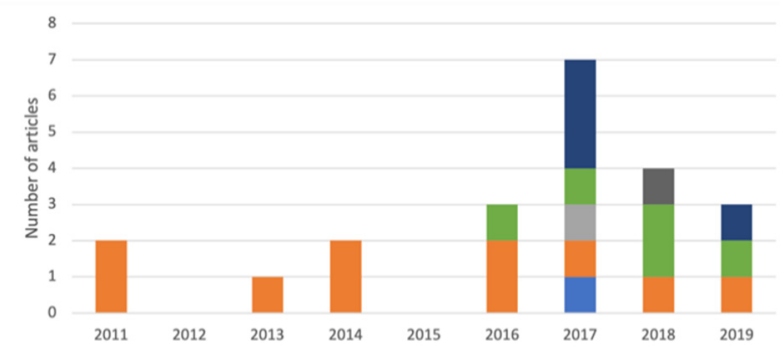

(b)

-3D Accelerometer, 3D Gyroscope and 3D Magnetometer + Barometer - 3D Accelerometer, 3D Gyroscope and 3D Magnetometer

- 3D Accelerometer and 3D Gyroscope

-3D Gyroscope

- 3 D Accelerometer + Pressure

=3D Accelerometer + Photoelectric HR

॥ 3 D Accelerometer + Barometer

- $3 \mathrm{D}$ Accelerometer

- 2D Accelerometer $+1 \mathrm{D}$ load cell

(d)

Figure A1. Information on number of articles using different types of sensors per publication year for: (a) all articles; (b) articles in Table 4; (c) articles in Tables 5 and 6; and (d) the sensor types. HR = heart rate. Please note that HR is used for heart rate only in this figure.

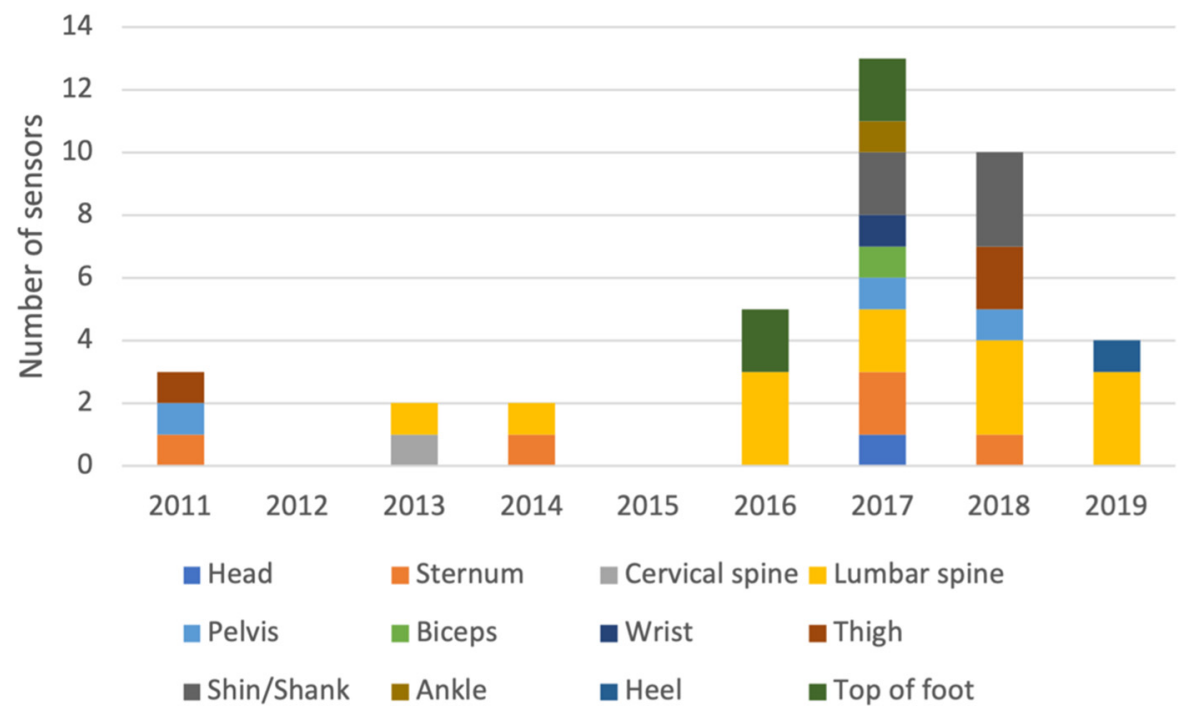

Figure A2. Number of sensors per body location for articles in Table 4, per publication year. 


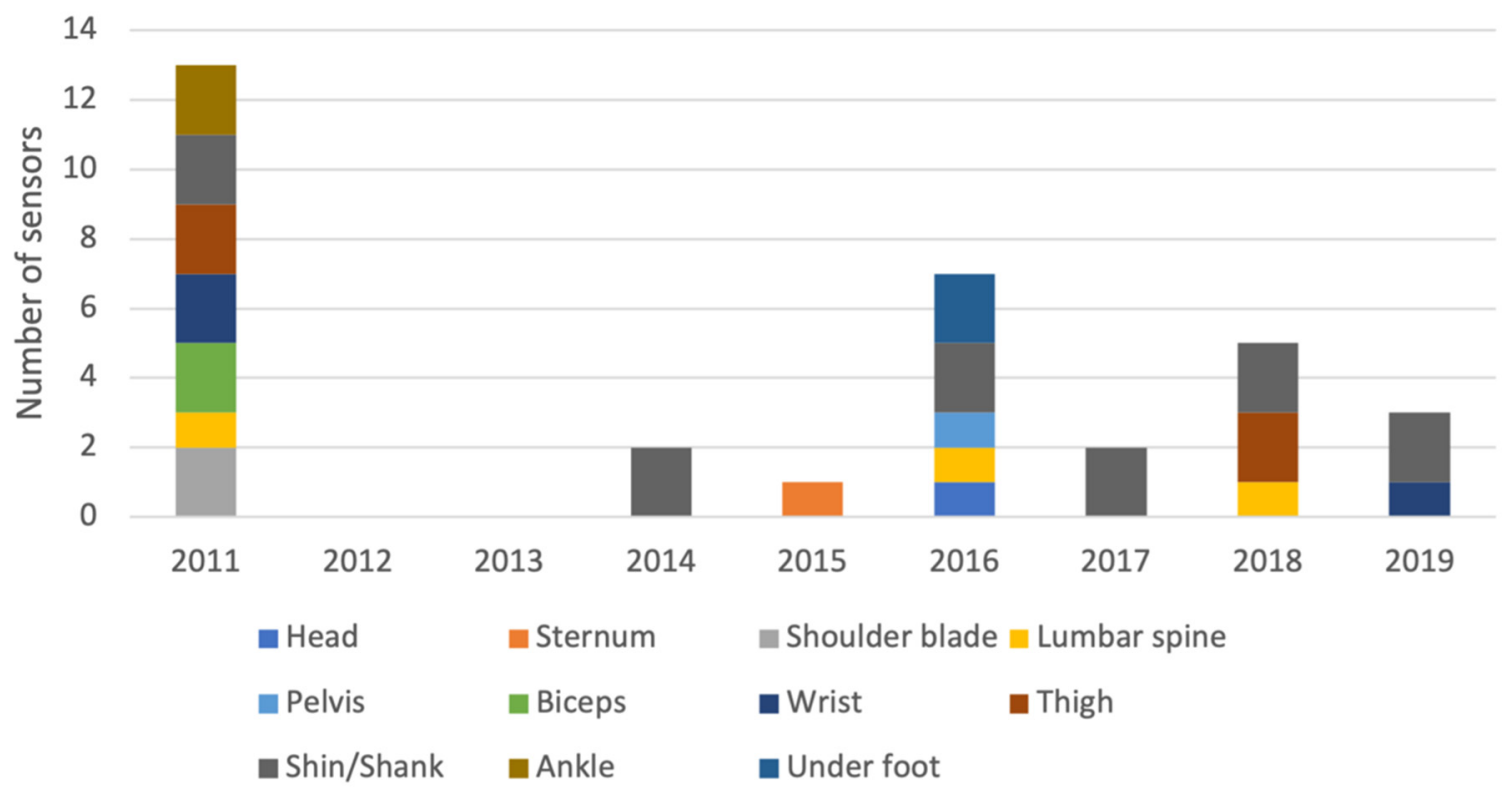

Figure A3. Number of sensors per body location for articles in Tables 5 and 6, per publication year.

\section{Appendix C}

This appendix provides complimentary information for the feature selection methods in Tables 4-6.

Table A2. Complimentary information for the feature selection methods in Table 4. COG = center of gravity, ICC = Intra-class correlation coefficient, SSQ = Simulator Sickness Questionnaire.

\begin{tabular}{ll}
\hline Ref No. & Feature Selection Methods \\
\hline & 1. Assessment of intra-and inter- observer reliability for gait parameters (ICC, CV of standard error of measurement) \\
2. Assessment of whether each parameter differed significantly between fallers/non-fallers and between walks \\
(ANOVA and $t$-test, Wilcoxon-signed-rank and Kruskall-Wallis tests for step time asymmetry) \\
3. Analysis of each gait parameters' predictive value (Stepwise logistic regression: forward likelihood ratio) \\
4. Analysis of discriminate capacity (ROC curve) \\
\hline 1. Assessment of whether each parameter differed significantly between repetitions for each participant (ANOVA) \\
2. Assessment of whether each parameter differed significantly between fallers/non-fallers (One-way ANOVA) \\
1. Assessment if whether characteristics and gait variables differed significantly between fallers/non-fallers \\
(independent $t$-tests or $\chi 2$ tests) \\
2. Analysis of each variable and falls incidence (Stepwise logistic regression: forward stepwise selection from all \\
variables that were significantly associated with falling), \\
3. Estimation of cut-off values for gait variables significantly associated with falling in logistic regression to predict \\
falls (ROC curve) \\
1. Assessment of whether SSI differed significantly between obstacle negotiation and baseline for controls/fallers \\
(Wilcoxon Signed Rank) \\
2. Assessment of whether SSI differed significantly between fallers/controls under s different walking conditions \\
(Mann-Whitney test)
\end{tabular}


Table A2. Cont.

\begin{tabular}{|c|c|}
\hline Ref No. & Feature Selection Methods \\
\hline [30] & $\begin{array}{l}\text { 1. Assessment of the abilities of median LDS of each individual parameter setting to distinguish fallers/non-fallers } \\
\text { (Univariate logistic regression with a } 10 \text {-fold CV and AUC) and testing significant discrimination ability of each } \\
\text { parameter setting (bootstrapping with } 2000 \text { resamples) } \\
\text { 2. Comparison the } 3 \text { algorithms' ability to distinguish fallers/non-fallers of best performing parameter setting } \\
\text { (Univariate logistic regression with a } 10 \text {-fold CV and AUC) } \\
\text { 3. Selection of the best performing model for the } 3 \text { algorithms (Stepwise multivariate logistic regression with } \\
\text { stepwise backward feature selection) }\end{array}$ \\
\hline [31] & Selection of RCME/RMPE metrics with highest discriminatory ability (PLS-DA with a backward feature selection) \\
\hline [33] & $\begin{array}{l}\text { 1. Assessment of whether each turning parameter differed significantly between non-fallers, single fallers, recurrent } \\
\text { fallers based on RE-12 (One-way ANOVA) } \\
\text { 2. Assessment of whether turning parameters differed significantly between non-fallers/fallers based on PRO-6 } \\
\text { (One-way ANOVA) }\end{array}$ \\
\hline [34] & $\begin{array}{l}\text { 1. Assessment of significant differences in postural sway (RMS and NPL sway in both AP and ML directions) } \\
\text { between balance tasks (Friedman test, Wilcoxon signed ranks test for post hoc pairwise comparisons) } \\
\text { 2. Assessment of test-retest reliability of lower extremity muscle strength (ICC) } \\
\text { 3. Analysis of association between postural sway and muscle strength with gait speed, number of comorbidities, } \\
\text { grip strength and frailty index (Spearman rank correlation) } \\
\text { 4. Assessment of whether body sway and lower extremity strength differed significantly between fallers/non-fallers } \\
\text { (Mann-Whitney U test) }\end{array}$ \\
\hline [35] & $\begin{array}{l}\text { 1. Assessment of univariate group difference in the demographics and the walking patterns of fallers and non-fallers } \\
\text { and further to adjust significant demographic differences between fallers/non-fallers (ANOVA, ANCOVA) } \\
\text { 2. Assessment of associations between demographic, health, sensorimotor, psychological, and cognitive factors with } \\
\text { the gait/mobility assessments (Pearson's correlation and Partial Pearson's correction (after adjusting for sex, age)) }\end{array}$ \\
\hline [37] & $\begin{array}{l}\text { 1. Assessment of whether each demographic parameter and adverse health outcomes differed significantly between } \\
\text { the UEF index defined groups (non-frail/frail) (ANOVA) } \\
\text { 2. Analysis of the association between the UEF index with each health outcome (Logistic regression (for nominal } \\
\text { health outcomes) and ANOVA regression (for continuous health outcomes)) }\end{array}$ \\
\hline [38] & $\begin{array}{l}\text { 1. Assessment of the SSQ-score pre-and post-exposure (one-sample } t \text {-test and signed rank test) } \\
\text { 2. Assessment of variable-module's test-retest reliability for in identifying differences between } 5 \text { experimental } \\
\text { conditions and baseline conditions (Paired } t \text {-test and Pearson's correlation) }\end{array}$ \\
\hline [39] & $\begin{array}{l}\text { Identification of key outcome measures with significant impact on faller status (faller/non-faller) (Stepwise logistic } \\
\text { regression, Pearson correlation to check multi-collinearity between all outcome measure pairs) }\end{array}$ \\
\hline [40] & $\begin{array}{l}\text { 1. Assessment of performance difference for TUG parameters between single task (ST), motor task (MT) and } \\
\text { cognitive dual-task (CT) conditions (MANCOVA) } \\
\text { 2. Assessment of the difference in individual parameters from the three TUG conditions between groups of } \\
\text { fallers/non-fallers (ANCOVA) }\end{array}$ \\
\hline [41] & $\begin{array}{l}\text { 1. Assessment of differences between fallers and non-multiple fallers (two-sample } t \text {-test, Fisher's exact test (for } \\
\text { gender), Mann-Whitney-U test (for age and BMI), Wilcoxon's signed-rank test (for pairwise differences in the gait } \\
\text { parameters from two contrasting terrains), Benjamini-Hochberg adjustments (to control for multiple } \\
\text { comparisons)) } \\
\text { 2. Logistic regression, Benjamini-Hochberg adjustments on } p \text {-values (to identify individual gait parameters that } \\
\text { were associated with multiple falls) }\end{array}$ \\
\hline [42] & $\begin{array}{l}\text { 1. Assessment of differences between fallers/non-fallers/multiple fallers in demographics and clinical and basic } \\
\text { gait assessment (Mann-Whitney U test) } \\
\text { 2. Analysis of each significant variable's strength to predict falls (Logistic regression and ROC curve) }\end{array}$ \\
\hline
\end{tabular}


Table A2. Cont.

\begin{tabular}{|c|c|}
\hline Ref No. & Feature Selection Methods \\
\hline [43] & $\begin{array}{l}\text { 1. Assessment of differences in socio-demographic parameters and subjective questionnaires among three balance } \\
\text { groups (One-way ANOVA model) } \\
\text { 2. Assessment of differences in balance parameters between groups (ANOVA models for normally distributed data } \\
\text { according to Shapiro-Wilk test, Friedman test with calculation of Cohen's effect size for data not normally } \\
\text { distributed according to Shapiro-Wilk test) } \\
\text { 3. Analysis of association between changes in COG sway body sway and changes with local-control(slope) and } \\
\text { central-control(slope-log) changes due to vibration (linear Pearson correlations) }\end{array}$ \\
\hline [44] & Assessment of differences in gait parameters between low-risk/high-risk patients (Independent samples $t$-test) \\
\hline [45] & $\begin{array}{l}\text { Assessment of whether the amount of DTW difference between reference and elderly fallers differed significantly } \\
\text { from DTW differences of elderly non-fallers and reference (ANOVA) } \\
\text { (DTW measures similarity in BST between elderly fallers and a reference BST) }\end{array}$ \\
\hline [47] & $\begin{array}{l}\text { 1. Assessment of normality of data (Shapiro-Wilk test) and of homoscedasticity (Levene's Test of Equality of } \\
\text { Variances) } \\
\text { 2.Assessment of falls history (faller/non-faller) on Micro and Macro gait characteristics (General linear modelling) } \\
\text { 3. For gait characteristics with a fall history interaction: Post hoc secondary analysis (Tukey's test) to identify } \\
\text { subgroups (fallers/non-fallers among OAs) that are significantly different from each other. }\end{array}$ \\
\hline [48] & $\begin{array}{l}\text { 1. Calculation of sway index (GMM, EM and MML algorithm) } \\
\text { 2. Assessment of differences between non-fallers/fallers / multiple fallers in standing sway indices and BBS } \\
\text { (ANOVA) } \\
\text { 3. Assessment of the performance of } 4 \text { sway indices and BBS in predicting (once- and multiple) fallers (ROC-curve) }\end{array}$ \\
\hline [50] & $\begin{array}{l}\text { 1. Assessment of differences in demographics and gait parameters between genders (unpaired } t \text {-tests/ } \chi^{2} \text { tests) } \\
\text { 2. Assessment of structural validity and sub-domain construct validity of the C-GAITS score (exploratory factor } \\
\text { analysis using Unweighted least squares as extraction method) } \\
\text { 3. Assessment of the internal consistency of the C-GAITS score (Cronbach's alpha coefficient) } \\
\text { 4. Assessment of correlation between C-GAITS score and walking speed (Single linear regression) } \\
\text { 5. Assessment of association of C-GAITS score and subscale scores with variables (Unpaired } t \text {-tests) }\end{array}$ \\
\hline
\end{tabular}

Table A3. Complimentary information for the feature selection methods in Table 5.

\begin{tabular}{|c|c|}
\hline Ref No. & Feature Selection Methods \\
\hline [22] & $\begin{array}{l}\text { 1. Assessment of significant differences between fallers and non-fallers in gait velocity and SagAngVel variables } \\
\text { (Mann-Whitney Wilcoxon rank sum) } \\
\text { 2. Assessment of correlation of each SagAngVel value with BBS score, manual TUG time, and gait velocity } \\
\text { (Pearson's correlation) }\end{array}$ \\
\hline [23] & $\begin{array}{l}\text { Pre-processing of multi-parameter datasets prior to classification modelling using a wrapper feature selection } \\
\text { algorithm to exclude parameters with low information (wrapper subset evaluator, employing the simple } \\
\text { logistic algorithm) }\end{array}$ \\
\hline [27] & Sequential forward feature selection within $\mathrm{CV}$ procedure \\
\hline [36] & $\begin{array}{l}\text { 1. } F R E_{\text {sensor }} \text { feature selection by using nested } \mathrm{CV} \\
\text { 2. Validation of } F R E_{\text {sensor }} \text { using an independent dataset }\end{array}$ \\
\hline [49] & $\begin{array}{l}\text { 1. Assessment of whether } \mathrm{FRE}_{\text {combined }} \text { differed significantly between fallers/non-fallers (one-way ANOVA) } \\
\text { 2. Assessment of whether mobility impairment scores (calculated from percentile scores of QTUG parameters } \\
\text { grouped in five functional categories) (one-way ANOVA) }\end{array}$ \\
\hline
\end{tabular}


Table A4. Complimentary information for the feature selection methods in Table 6.

\begin{tabular}{|c|c|}
\hline Ref No. & Feature Selection Methods \\
\hline [20] & $\begin{array}{l}\text { 1. Assessment of significant differences between fallers and non-fallers in each feature ( } t \text {-test using Holm } \\
\text { correction, Behrens-Fisher test) } \\
\text { 2. Feature selection (Method in the forward wrapper selection algorithm family }\end{array}$ \\
\hline [28] & $\begin{array}{l}\text { 1.Assessment of associations between functional stair performance and participants characteristics (Spearman's } \\
\text { rank correlations) } \\
\text { 2.Assessment of post-hoc medians and interquartile ranges (IQR) of stair climbing performance for subgroups with } \\
\text { different stair-ascent strategies (Kruskal-Wallis) }\end{array}$ \\
\hline [29] & $\begin{array}{l}\text { 1. Assessment of the ability of models to classify fallers /non-fallers based (Acc, F1-score, MCC) } \\
\text { 2. Ranking analysis for each model type: (a) NB models }(n=62),(\text { b) SVM models }(n=155),(\text { c) NN models }(n=155) \\
\text { 3. Ranking analysis of best performing models for NB, SVM, NN models (15 of each) and ClinAsses models (5) }\end{array}$ \\
\hline [32] & $\begin{array}{l}\text { 1. Assessment of the ability of the entire feature set to discriminate between the groups of older fallers/non-fallers } \\
\text { (4 machine learning algorithms in Matlab) } \\
\text { 2.Assessment of the ability of the individual features to distinguish between older fallers/non-fallers (Linear } \\
\text { regression analysis) }\end{array}$ \\
\hline [46] & $\begin{array}{l}\text { 1. Assessment of whether each of the } 155 \text { outcome measures differed significantly between faller/non-faller groups } \\
\text { (two-sample } t \text {-tests) } \\
\text { 2. Assessment of discriminative power of each of the } 38 \text { measures (ROC analysis) } \\
\text { 3. Building models to classify faller/non-faller by use of } 6 \text { supervised machine learning models incorporating the } 38 \\
\text { significant measures as predictor variables and fall status as response variable } \\
\text { 4. Validation of classification models ( } 10 \text {-fold CV): Acc } \\
\text { 5. Statistical analysis of overall classification accuracy of SVM and the } 5 \text { other models (two-sample } t \text {-test) }\end{array}$ \\
\hline [51] & $\begin{array}{l}\text { 1. Wearable data tested for normality (Shapiro-Wilks) } \\
\text { 2. Assessment of whether means (or median) of each variable differed significantly between groups } \\
\text { non-fallers/once-fallers /multiple-fallers (one-way ANOVA or Kruskal-Wallis H test) } \\
\text { 3. Assessment of differences between groups with repeated measurements of physical activity, heart rate, and night } \\
\text { sleep (two-way ANOVA) } \\
\text { 4. Building models and evaluating their performance for three-class and binary fall risk classification (POM, logistic } \\
\text { regression, DT, RF) including (a) Removal of collinear variables (multicollinear test); (b) Ranking the variables } \\
\text { (predictors) importance in fall risk classification (recursive feature algorithm in Caret R package); (c) Training } \\
\text { models on wearable, RAI-HC, wearable + RAI-HC }\end{array}$ \\
\hline
\end{tabular}

\section{References}

1. World Health Organization. Falls. Available online: https://www.who.int/news-room/fact-sheets/detail/falls (accessed on 6 August 2021).

2. Rubenstein, L.Z.; Josephson, K.R. Falls and their prevention in elderly people: What does the evidence show? Med. Clin. N. Am. 2006, 90, 807-824. [CrossRef] [PubMed]

3. Stevens, J.A.; Corso, P.S.; Finkelstein, E.A.; Miller, T.R. The costs of fatal and non-fatal falls among older adults. Inj. Prev. 2006, 12, 290-295. [CrossRef]

4. Ambrose, A.F.; Paul, G.; Hausdorff, J.M. Risk factors for falls among older adults: A review of the literature. Maturitas 2013, 75, 51-61. [CrossRef]

5. Gillespie, L.D.; Robertson, M.C.; Gillespie, W.J.; Sherrington, C.; Gates, S.; Clemson, L.M.; Lamb, S.E. Interventions for preventing falls in older people living in the community. Cochrane Database Syst. Rev. 2012, 2012, CD007146. [CrossRef] [PubMed]

6. Hamm, J.; Money, A.G.; Atwal, A.; Paraskevopoulos, I. Fall prevention intervention technologies: A conceptual framework and survey of the state of the art. J. Biomed. Inform. 2016, 59, 319-345. [CrossRef]

7. Shany, T.; Redmond, S.J.; Marschollek, M.; Lovell, N.H. Assessing fall risk using wearable sensors: A practical discussion. A review of the practicalities and challenges associated with the use of wearable sensors for quantification of fall risk in older people. Z. Gerontol. Geriatr. 2012, 45, 694-706. [CrossRef] [PubMed]

8. Howcroft, J.; Kofman, J.; Lemaire, E.D. Review of fall risk assessment in geriatric populations using inertial sensors. J. Neuroeng. Rehabil. 2013, 10, 1-12. [CrossRef]

9. Shany, T.; Wang, K.; Liu, Y.; Lovell, N.H.; Redmond, S.J. Review: Are we stumbling in our quest to find the best predictor? Over-optimism in sensor-based models for predicting falls in older adults. Healthc. Technol. Lett. 2015, 2, 79-88. [CrossRef]

10. Palumbo, P.; Palmerini, L.; Chiari, L. A probabilistic model to investigate the properties of prognostic tools for falls. Methods Inf. Med. 2015, 54, 189-197. [CrossRef] 
11. Harrell, F.E., Jr.; Lee, K.L.; Mark, D.B. Multivariable prognostic models: Issues in developing models, evaluating assumptions and adequacy, and measuring and reducing errors. Stat. Med. 1996, 15, 361-387. [CrossRef]

12. Roeing, K.L.; Hsieh, K.L.; Sosnoff, J.J. A systematic review of balance and fall risk assessments with mobile phone technology. Arch. Gerontol. Geriatr. 2017, 73, 222-226. [CrossRef]

13. Sun, R.P.; Sosnoff, J.J. Novel sensing technology in fall risk assessment in older adults: A systematic review. BMC Geriatr. 2018, 18, 14. [CrossRef]

14. Montesinos, L.; Castaldo, R.; Pecchia, L. Wearable Inertial Sensors for Fall Risk Assessment and Prediction in Older Adults: A Systematic Review and Meta-Analysis. IEEE Trans. Neural. Syst. Rehabil. Eng. 2018, 26, 573-582. [CrossRef]

15. Rucco, R.; Sorriso, A.; Liparoti, M.; Ferraioli, G.; Sorrentino, P.; Ambrosanio, M.; Baselice, F. Type and Location of Wearable Sensors for Monitoring Falls during Static and Dynamic Tasks in Healthy Elderly: A Review. Sensors 2018, 18, 1613. [CrossRef]

16. Bet, P.; Castro, P.C.; Ponti, M.A. Fall detection and fall risk assessment in older person using wearable sensors: A systematic review. Int. J. Med. Inform. 2019, 130, 103946. [CrossRef]

17. Moher, D.; Liberati, A.; Tetzlaff, J.; Altman, D.G.; Group, P. Preferred reporting items for systematic reviews and meta-analyses: The PRISMA statement. PLoS Med. 2009, 6, e1000097. [CrossRef]

18. Luijendijk, H.J. How to create PICO questions about diagnostic tests. BMJ Evid. Based Med. 2021. [CrossRef]

19. Bautmans, I.; Jansen, B.; Van Keymolen, B.; Mets, T. Reliability and clinical correlates of 3D-accelerometry based gait analysis outcomes according to age and fall-risk. Gait Posture 2011, 33, 366-372. [CrossRef]

20. Caby, B.; Kieffer, S.; de Saint Hubert, M.; Cremer, G.; Macq, B. Feature extraction and selection for objective gait analysis and fall risk assessment by accelerometry. Biomed. Eng. Online 2011, 10, 1. [CrossRef] [PubMed]

21. Doheny, E.P.; Fan, C.W.; Foran, T.; Greene, B.R.; Cunningham, C.; Kenny, R.A. An instrumented sit-to-stand test used to examine differences between older fallers and non-fallers. In Proceedings of the 2011 33rd Annual International Conference of the IEEE Engineering in Medicine and Biology Society (EMBC), Boston, MA, USA, 30 August-3 September 2011; Volume 2011, pp. 3063-3066. [CrossRef]

22. Greene, B.R.; McGrath, D.; Foran, T.G.; Doheny, E.P.; Caulfield, B. Body-worn sensor based surrogates of minimum ground clearance in elderly fallers and controls. In Proceedings of the 2011 33rd Annual International Conference of the IEEE Engineering in Medicine and Biology Society (EMBC), Boston, MA, USA, 30 August-3 September 2011; Volume 2011, pp. 6499-6502. [CrossRef]

23. Marschollek, M.; Rehwald, A.; Wolf, K.H.; Gietzelt, M.; Nemitz, G.; zu Schwabedissen, H.M.; Schulze, M. Sensors vs. experts—A performance comparison of sensor-based fall risk assessment vs. conventional assessment in a sample of geriatric patients. BMC Med. Inform. Decis. Mak. 2011, 11, 48. [CrossRef]

24. Doi, T.; Hirata, S.; Ono, R.; Tsutsumimoto, K.; Misu, S.; Ando, H. The harmonic ratio of trunk acceleration predicts falling among older people: Results of a 1-year prospective study. J. Neuroeng. Rehabil. 2013, 10, 7. [CrossRef]

25. Cui, X.; Peng, C.K.; Costa, M.D.; Weiss, A.; Goldberger, A.L.; Hausdorff, J.M. Development of a new approach to quantifying stepping stability using ensemble empirical mode decomposition. Gait Posture 2014, 39, 495-500. [CrossRef]

26. Ejupi, A.; Brodie, M.; Gschwind, Y.J.; Schoene, D.; Lord, S.; Delbaere, K. Choice stepping reaction time test using exergame technology for fall risk assessment in older people. In Proceedings of the 2014 36th Annual International Conference of the IEEE Engineering in Medicine and Biology Society (EMBC), Chicago, IL, USA, 26-30 August 2014; Volume 2014, pp. 6957-6960. [CrossRef]

27. Greene, B.R.; McGrath, D.; Caulfield, B. A comparison of cross-sectional and prospective algorithms for falls risk assessment. In Proceedings of the 2014 36th Annual International Conference of the IEEE Engineering in Medicine and Biology Society (EMBC), Chicago, IL, USA, 26-30 August 2014; Volume 2014, pp. 4527-4530. [CrossRef]

28. Brodie, M.A.; Wang, K.J.; Delbaere, K.; Persiani, M.; Lovell, N.H.; Redmond, S.J.; Del Rosario, M.B.; Lord, S.R. New Methods to Monitor Stair Ascents Using a Wearable Pendant Device Reveal How Behavior, Fear, and Frailty Influence Falls in Octogenarians. IEEE Trans. Biomed. Eng. 2015, 62, 2595-2601. [CrossRef]

29. Howcroft, J.; Lemaire, E.D.; Kofman, J. Wearable-Sensor-Based Classification Models of Faller Status in Older Adults. PLoS ONE 2016, 11, e0153240. [CrossRef]

30. Ihlen, E.A.F.; Weiss, A.; Beck, Y.; Helbostad, J.L.; Hausdorff, J.M. A comparison study of local dynamic stability measures of daily life walking in older adult community-dwelling fallers and non-fallers. J. Biomech. 2016, 49, 1498-1503. [CrossRef] [PubMed]

31. Ihlen, E.A.F.; Weiss, A.; Bourke, A.; Helbostad, J.L.; Hausdorff, J.M. The complexity of daily life walking in older adult communitydwelling fallers and non-fallers. J. Biomech. 2016, 49, 1420-1428. [CrossRef] [PubMed]

32. Iluz, T.; Weiss, A.; Gazit, E.; Tankus, A.; Brozgol, M.; Dorfman, M.; Mirelman, A.; Giladi, N.; Hausdorff, J.M. Can a Body-Fixed Sensor Reduce Heisenberg's Uncertainty When It Comes to the Evaluation of Mobility? Effects of Aging and Fall Risk on Transitions in Daily Living. J. Gerontol. A Biol. Sci. Med. Sci. 2016, 71, 1459-1465. [CrossRef]

33. Mancini, M.; Schlueter, H.; El-Gohary, M.; Mattek, N.; Duncan, C.; Kaye, J.; Horak, F.B. Continuous Monitoring of Turning Mobility and Its Association to Falls and Cognitive Function: A Pilot Study. J. Gerontol. A Biol. Sci. Med. Sci. 2016, 71, 1102-1108. [CrossRef]

34. Alqahtani, B.A.; Ferchak, M.A.; Huppert, T.J.; Sejdic, E.; Perera, S.; Greenspan, S.L.; Sparto, P.J. Standing balance and strength measurements in older adults living in residential care communities. Aging Clin. Exp. Res. 2017, 29, 1021-1030. [CrossRef] 
35. Brodie, M.A.; Coppens, M.J.; Ejupi, A.; Gschwind, Y.J.; Annegarn, J.; Schoene, D.; Wieching, R.; Lord, S.R.; Delbaere, K. Comparison between clinical gait and daily-life gait assessments of fall risk in older people. Geriatr. Gerontol. Int. 2017, 17, 2274-2282. [CrossRef]

36. Greene, B.R.; Redmond, S.J.; Caulfield, B. Fall Risk Assessment through Automatic Combination of Clinical Fall Risk Factors and Body-Worn Sensor Data. IEEE J. Biomed. Health Inform. 2017, 21, 725-731. [CrossRef] [PubMed]

37. Joseph, B.; Toosizadeh, N.; Orouji Jokar, T.; Heusser, M.R.; Mohler, J.; Najafi, B. Upper-Extremity Function Predicts Adverse Health Outcomes among Older Adults Hospitalized for Ground-Level Falls. Gerontology 2017, 63, 299-307. [CrossRef] [PubMed]

38. Saldana, S.J.; Marsh, A.P.; Rejeski, W.J.; Haberl, J.K.; Wu, P.; Rosenthal, S.; Ip, E.H. Assessing balance through the use of a low-cost head-mounted display in older adults: A pilot study. Clin. Interv. Aging 2017, 12, 1363-1370. [CrossRef] [PubMed]

39. Sample, R.B.; Kinney, A.L.; Jackson, K.; Diestelkamp, W.; Bigelow, K.E. Identification of key outcome measures when using the instrumented timed up and go and/or posturography for fall screening. Gait Posture 2017, 57, 168-171. [CrossRef]

40. Smith, E.; Walsh, L.; Doyle, J.; Greene, B.; Blake, C. Effect of a dual task on quantitative Timed Up and Go performance in community-dwelling older adults: A preliminary study. Geriatr. Gerontol. Int. 2017, 17, 1176-1182. [CrossRef] [PubMed]

41. Wang, K.; Delbaere, K.; Brodie, M.A.D.; Lovell, N.H.; Kark, L.; Lord, S.R.; Redmond, S.J. Differences Between Gait on Stairs and Flat Surfaces in Relation to Fall Risk and Future Falls. IEEE J. Biomed. Health Inform. 2017, 21, 1479-1486. [CrossRef] [PubMed]

42. Bizovska, L.; Svoboda, Z.; Janura, M.; Bisi, M.C.; Vuillerme, N. Local dynamic stability during gait for predicting falls in elderly people: A one-year prospective study. PLOS ONE 2018, 13, e0197091. [CrossRef]

43. Ehsani, H.; Mohler, J.; Marlinski, V.; Rashedi, E.; Toosizadeh, N. The influence of mechanical vibration on local and central balance control. J. Biomech. 2018, 71, 59-66. [CrossRef]

44. Genovese, V.; Mannini, A.; Guaitolini, M.; Sabatini, A.M. Wearable Inertial Sensing for ICT Management of Fall Detection, Fall Prevention, and Assessment in Elderly. Technologies 2018, 6, 91. [CrossRef]

45. Ghahramani, M.; Naghdy, F.; Stirling, D.; Naghdy, G.; Potter, J.; Roach, M. Assessing the Risk of Fall in Older People through Turning Test. In Proceedings of the 2018 IEEE International Symposium on Medical Measurements and Applications (MeMeA), Rome, Italy, 11-13 June 2018; pp. 1-6. [CrossRef]

46. Qiu, H.; Rehman, R.Z.U.; Yu, X.; Xiong, S. Application of Wearable Inertial Sensors and A New Test Battery for Distinguishing Retrospective Fallers from Non-fallers among Community-dwelling Older People. Sci. Rep. 2018, 8, 16349. [CrossRef]

47. Del Din, S.; Galna, B.; Godfrey, A.; Bekkers, E.M.J.; Pelosin, E.; Nieuwhof, F.; Mirelman, A.; Hausdorff, J.M.; Rochester, L. Analysis of Free-Living Gait in Older Adults With and Without Parkinson's Disease and With and Without a History of Falls: Identifying Generic and Disease-Specific Characteristics. J. Gerontol. A Biol. Sci. Med. Sci. 2019, 74, 500-506. [CrossRef] [PubMed]

48. Ghahramani, M.; Stirling, D.; Naghdy, F.; Naghdy, G.; Potter, J. Body postural sway analysis in older people with different fall histories. Med. Biol. Eng. Comput. 2019, 57, 533-542. [CrossRef]

49. Greene, B.R.; McManus, K.; Redmond, S.J.; Caulfield, B.; Quinn, C.C. Digital assessment of falls risk, frailty, and mobility impairment using wearable sensors. NPJ Digit. Med. 2019, 2, 125. [CrossRef] [PubMed]

50. Misu, S.; Asai, T.; Doi, T.; Sawa, R.; Ueda, Y.; Murata, S.; Saito, T.; Sugimoto, T.; Isa, T.; Tsuboi, Y.; et al. Development and validation of Comprehensive Gait Assessment using InerTial Sensor score (C-GAITS score) derived from acceleration and angular velocity data at heel and lower trunk among community-dwelling older adults. J. Neuroeng. Rehabil. 2019, 16, 62. [CrossRef]

51. Yang, Y.; Hirdes, J.P.; Dubin, J.A.; Lee, J. Fall Risk Classification in Community-Dwelling Older Adults Using a Smart WristWorn Device and the Resident Assessment Instrument-Home Care: Prospective Observational Study. JMIR Aging 2019, 2, e12153. [CrossRef]

52. Ihlen, E.A.; Goihl, T.; Wik, P.B.; Sletvold, O.; Helbostad, J.; Vereijken, B. Phase-dependent changes in local dynamic stability of human gait. J. Biomech. 2012, 45, 2208-2214. [CrossRef]

53. Kantz, H. A robust method to estimate the maximal Lyapunov exponent of a time series. Phys. Lett. A 1994, 185, 77-87. [CrossRef]

54. Rosenstein, M.T.; Collins, J.J.; De Luca, C.J. A practical method for calculating largest Lyapunov exponents from small data sets. Phys. D Nonlinear Phenom. 1993, 65, 117-134. [CrossRef]

55. Cummings, S.R.; Nevitt, M.C.; Kidd, S. Forgetting falls. The limited accuracy of recall of falls in the elderly. J. Am. Geriatr. Soc. 1988, 36, 613-616. [CrossRef]

56. Concato, J.; Feinstein, A.R.; Holford, T.R. The risk of determining risk with multivariable models. Ann. Intern. Med. 1993, 118, 201-210. [CrossRef]

57. King, G.; Zeng, L. Logistic Regression in Rare Events Data. Political Anal. 2001, 9, 137-163. [CrossRef]

58. Isaksson, A.; Wallman, M.; Göransson, H.; Gustafsson, M.G. Cross-validation and bootstrapping are unreliable in small sample classification. Pattern Recognit. Lett. 2008, 29, 1960-1965. [CrossRef] 